OPEN ACCESS

Edited by:

Juan Pablo de Rivero Vaccari, University of Miami, United States

Reviewed by: Uday Kishore,

Brunel University London, United Kingdom Won-Suk Chung,

Korea Advanced Institute of Science and Technology, South Korea

*Correspondence:

Candace Strang proteinpartners@gmail.com

Received: 21 October 2020 Accepted: 12 January 2021 Published: 04 March 2021

Citation:

Peoples N and Strang C (2021) Complement Activation in the Central Nervous System: A Biophysical Model

for Immune Dysregulation in the

Disease State.

Front. Mol. Neurosci. 14:620090. doi: 10.3389/fnmol.2021.620090

\section{Complement Activation in the Central Nervous System: A Biophysical Model for Immune Dysregulation in the Disease State}

\author{
Nicholas Peoples ${ }^{1}$ and Candace Strang ${ }^{2 *}$ \\ ${ }^{1}$ Baylor College of Medicine, Houston, TX, United States, ${ }^{2}$ IPPIN Biomarkers, Inc., Arlington, MA, United States
}

Complement, a feature of the innate immune system that targets pathogens for phagocytic clearance and promotes inflammation, is tightly regulated to prevent damage to host tissue. This regulation is paramount in the central nervous system (CNS) since complement proteins degrade neuronal synapses during development, homeostasis, and neurodegeneration. We propose that dysregulated complement, particularly $\mathrm{C} 1$ or C3b, may errantly target synapses for immune-mediated clearance, therefore highlighting regulatory failure as a major potential mediator of neurological disease. First, we explore the mechanics of molecular neuroimmune relationships for the regulatory proteins: Complement Receptor 1, C1-Inhibitor, Factor H, and the CUB-sushi multiple domain family. We propose that biophysical and chemical principles offer clues for understanding mechanisms of dysregulation. Second, we describe anticipated effects to CNS disease processes (particularly Alzheimer's Disease) and nest our ideas within existing basic science, clinical, and epidemiological findings. Finally, we illustrate how the concepts presented within this manuscript provoke new ways of approaching age-old neurodegenerative processes. Every component of this model is testable by straightforward experimentation and highlights the untapped potential of complement dysregulation as a driver of CNS disease. This includes a putative role for complementbased neurotherapeutic agents and companion biomarkers.

Keywords: CR1, factor H, C1 inhibitor, complement, neuroimmune, Alzheimer's disease, schizophrenia

\section{INTRODUCTION}

The basic features of complement, with three separate activation processes that converge into a common pathway for immune signaling and pathogen clearance, are well-understood (Merle et al., 2015a,b; Murphy and Weaver, 2016). The classical complement pathway (CCP) identifies immune complexes of IgG or IgM and certain other macromolecules independently of antibody (Figure 1a). The alternative pathway activates in an antibody-independent manner when Complement $\mathrm{C} 3$ spontaneously hydrolyzes into $\mathrm{C} 3\left(\mathrm{H}_{2} \mathrm{O}\right)$ and combines with complement factor $\mathrm{Bb}$ (Figure $\mathbf{1 b}$ ). Activation of either pathway triggers a cascade of enzyme reactions, chemotactic signaling to nearby immune cells, and tagging the pathogen for removal by immune cell-mediated uptake (Figure 1c). The rapid, exponential activation of this defense system provides immediate protection to the host, but also the possibility of great damage if the regulatory brakes fail. The first step of pathogen recognition is the only molecular recognition 


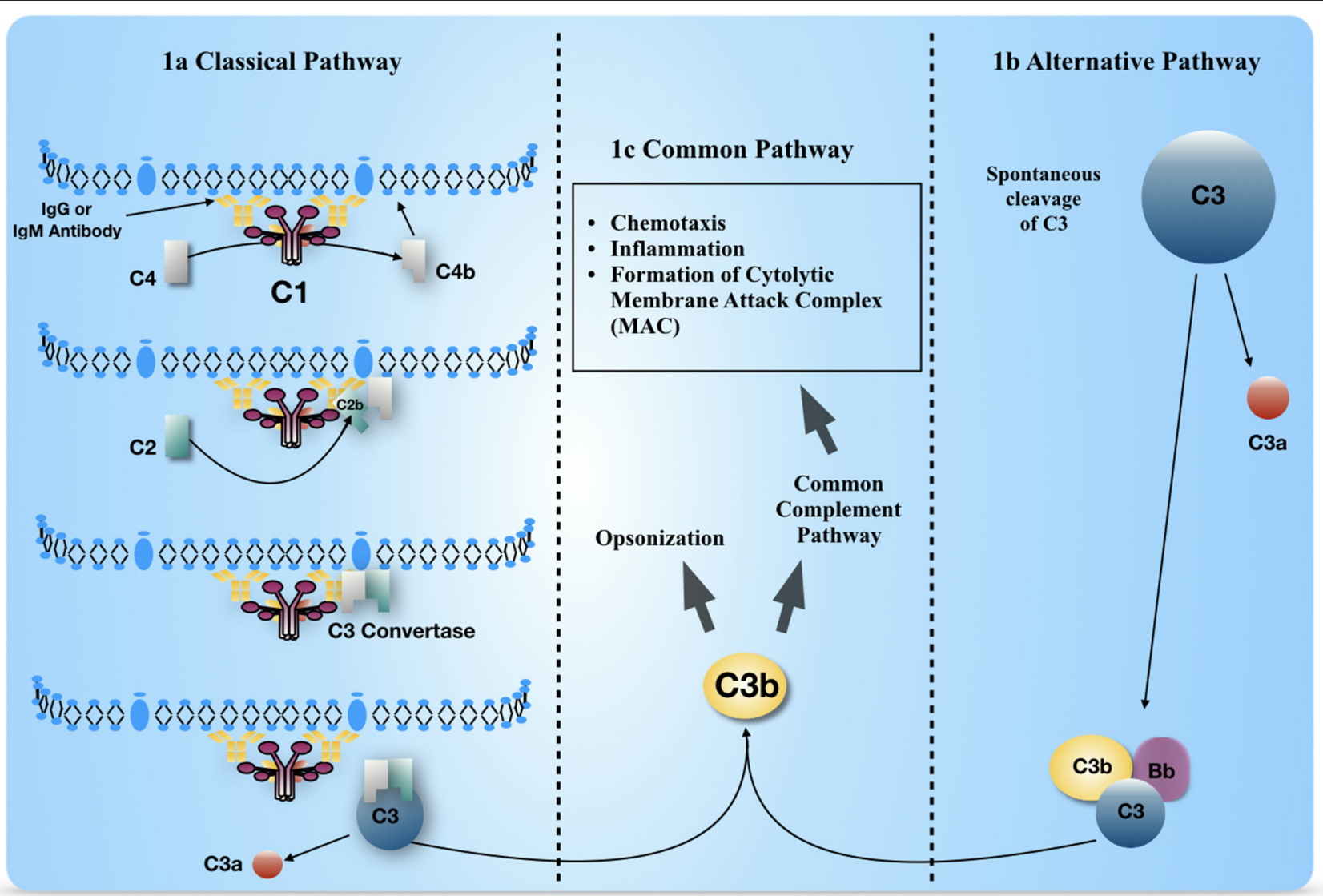

FIGURE 1 | Elements of the classical and alternative complement pathways, separated by the unique and common aspects. (a) Early steps of the classical pathway, to show activation and generation of C3 convertase enzymatic activity. C4b (soluble) is converted to C4b (membrane bound) via a thiol ester transesterification reaction (not shown in figure). (b) Early steps of the alternative pathway to show activation and generation of C3 convertase enzymatic activity. (c) Common aspects of complement pathway activation that result in macrophage and neutrophil recruitment and formation of the membrane attack complex, a cytolytic pore on the pathogen surface.

event for definitive pathogen identification. All subsequent steps in complement activation occur in a programmed fashion. Therefore, several regulatory elements limit activation of complement to ensure complement only targets unwanted material and not host tissue.

Until 1998, a mistaken assumption pervaded the scientific community that the brain did not have its own immunity due to protection behind the blood brain barrier (BBB). This erroneous assumption was exposed upon demonstration of $\mathrm{MHC}$ I cell surface markers for self in the brain by Carla Shatz and coworkers (Corriveau et al., 1998). Shortly after, several groups demonstrated evidence of complement protein synthesis in the brain (Terai et al., 1997; Singhrao et al., 1999). Baseline CNS complement levels are made by microglia, and, under stressful conditions (e.g., oxidative stress and inflammation), can be made by neurons and astrocytes (Kolev et al., 2009). Over the next two decades researchers detailed how the CCP is used to selectively remove unused or damaged synapses (Stevens et al., 2007; Chu et al., 2010; Sekar et al., 2016) in a process called synaptic pruning. Remarkably, only a fraction of synapses is removed at any one time in a directed fashion that is not fully understood. Given this specialized and discriminating function, tight regulation of complement is paramount to ensure precision removal of only unwanted synapses.

There are two distinctive features of CNS complement. The first is that complement can be activated to remove select parts of host cells as a natural aspect of development. In neuronal development, older cells are sometimes removed in anatomical development with changes with maturity to an adult pattern. Complement participates in this removal process (Stevens et al., 2007, 2018; Coulthard et al., 2018; Presumey et al., 2018). The second feature is the elimination of neuronal synapses thought to be damaged in neurodegenerative diseases such as $\mathrm{AD}$. In $\mathrm{AD}$, it has long been known that complement binds to neurofibrillary tangles (NfT) and amyloid plaques (Eikelenboom et al., 1989; Rogers et al., 1992; Shen et al., 2001; Tacnet-Delorme et al., 2001; Hong et al., 2016). More recent studies, using high-resolution microscopy techniques, have yielded a remarkable picture of complement proteins at the synapse (Dejanovic et al., 2018; Litvinchuk et al., 
2018) (Figure 2). In AD, reduced synaptic density corresponds to altered synaptic plasticity (Sheng et al., 2012), such as impaired long-term potentiation (LTP) and enhanced long-term depression (LTD), leading to cognitive impairment. Complement activity participates in synapse removal.

CNS complement is capable of clearing fragments of host cells and synaptic connections in the brain, both in development and in disease. This underscores a clear concept for neurological disease. We therefore hypothesize that overactive or underactive (i.e., dysregulated) complement activity may create a pattern of abnormal circuitry in the brain. If the level of synaptic clearance is too low, excess synaptic connections may lead to aberrant activity (e.g., hyperactivity, seizures, lack of definitive signaling circuitry). If the level of synaptic clearance is too high, insufficient circuitry remains and neurodegenerative conditions are created. Moreover, complement directly binds NfT and amyloid, underscoring a link to the progression in $\mathrm{AD}$. Other publications have elegantly described several aspects of complement activity in the CNS, including location, microglial interactions, and pharmacologic inhibition (Veerhuis et al., 2011; Shen et al., 2013; Morgan, 2018; Bohlen et al., 2019; Wilton et al., 2019). This paper highlights a critical missing piece, calling attention to regulatory failure as a major potential mediator of CNS disease. First, we propose pathogenic variants of regulatory complement proteins (Factor H, Complement Receptor 1) may result in excess $\mathrm{C} 3 \mathrm{~b}$ and failure to protect host tissue. Second, we illustrate how simultaneous activation of the complement and contact pathways may overwhelm C1-inhibitor, producing potentially catastrophic prolonged activation of the entire complement pathway. Finally, we suggest putative roles for CUB Sushi multiple domain proteins as complement control proteins and raise the intriguing question of whether their unique domain structure could imply participation in cell-signaling complexes at the post-synaptic density. Collectively, this model offers a unique perspective on neuroimmune relationships. Each component spurs new directions for interdisciplinary, highimpact research and underscores the potential of complementbased neurotherapeutic approaches.

\section{DISEASE MUTATIONS OF REGULATORS OF COMPLEMENT ACTIVATION PROTEINS LEAD TO INCREASED COMPLEMENT ACTIVITY}

\section{Excess C3b Can Damage Host Tissue}

$\mathrm{C} 3 \mathrm{~b}$ is the foremost signaling fragment that provides the "EAT ME" opsonization marker recognized by surface receptors on phagocytic immune cells. Soluble C3b remains capable of generating phagocytic complement activity as it diffuses away from the original pathogenic target and it has no special recognition capacity to distinguish a pathogen vs. self-cell. It is therefore critical to limit the number of $\mathrm{C} 3 \mathrm{~b}$ fragments that are generated, either by inhibiting the $\mathrm{C} 3$ convertase or catalyzing $\mathrm{C} 3 \mathrm{~b}$ into iC3b (inactivated C3b).

The Regulation of Complement Activation (RCA) proteins each play a role in limiting the level of biologically active
C3b. This family of proteins are encoded in a gene cluster on chromosome 1 and are characterized by a quaternary structure that are repeats of the so-called "Sushi" domain, a conserved fivestranded $\beta$-sheet domain of $\sim 60$ amino acids (Furtado et al., 2008; Wu et al., 2009; Forneris et al., 2016; Xue et al., 2016). They fall into two categories: soluble or membrane bound. Soluble regulators are critical for limiting the amount of $\mathrm{C} 3 \mathrm{~b}$ generated; membrane-bound regulators remove errantly bound $\mathrm{C} 3 \mathrm{~b}$ from the surface of host cells. The ensuing section will discuss Factor $\mathrm{H}$, a soluble RCA protein, and the section following that will consider Complement Receptor 1, a membrane bound RCA protein, in great detail.

\section{Mutations in Factor H Can Create Excess C3b}

The soluble RCA proteins, such as Factor $\mathrm{H}$, are diffusible factors that serve to regulate both soluble and cell-bound C3 convertase enzymes of complement. Mutations in Factor $\mathrm{H}$ handicap its ability to dissociate the alternative pathway $\mathrm{C} 3$ convertase (Figure 3) and/or directly cleave C3b to iC3b with the assistance of the soluble protease factor I. The result is excess $\mathrm{C} 3 \mathrm{~b}$ and limited conversion to $\mathrm{iC} 3 \mathrm{~b}$ which may override host protection mechanisms, aberrantly allowing $\mathrm{C} 3 \mathrm{~b}$ to signal for host tissue to be cleared. This excess C3b can be soluble, diffusible, and a ligand for any of the cell-bound RCA proteins. This process is documented in the periphery, where Factor $\mathrm{H}$ mutations are associated with eye and kidney disease (Ferreira et al., 2010). CNS tissue is densely packed (where diffusing C3b could easily land on an improper target), and Factor $\mathrm{H}$ is a risk factor for AD (Zhang et al., 2016) and schizophrenia (Boyajyan et al., 2010), so the concept of CNS-centered disease is well within reason.

Proteins unique to the classical complement pathway are risk factors for AD (Jones et al., 2010). Specifically, MHC III proteins which directly impact the formation and disassembly of the various $\mathrm{C} 3$ convertases (Factor B, C2, C4) are risk factors for $\mathrm{AD}$ (Alzheimer Forum Chromosomal location for $\mathrm{AD}$ risk genes) and schizophrenia (Sekar et al., 2016; Woo et al., 2020). Since both formation (C2, Factor B) and clearance (factor $\mathrm{H}$ ) of the $\mathrm{C} 3$ convertase are processes influenced by disease risk factors, it is reasonable that $\mathrm{C} 3 \mathrm{~b}$ may be a pivot point in CNS complement biology and its level dictates the effectiveness of this immune clearance function. The classical complement pathway in the CNS proceeds at least up to the point of C3 cleavage. Immunohistochemical studies have not yet progressed to the level of extensive complement factor analysis, however, so we suggest this is a valuable area for future research.

\section{Complement Receptor 1 Is Strongly Associated With Alzheimer's Disease and Mutations May Lead to Aberrant C3b Deposition and Clearance of Neurons}

Complement Receptor 1 (CR1), a membrane-bound RCA protein, is located on neurons (Lian and Zheng, 2016) and cells in their immediate vicinity (Lucin and Wyss-Coray, 2009). CR1 is among the top 10 risk factors for AD (Lambert et al., 2009; Jun 
A Timeline for the P301S tauopathy mouse

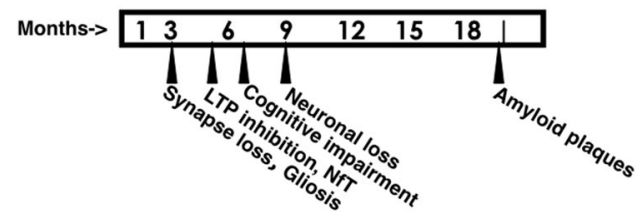

B C1q at the synapse

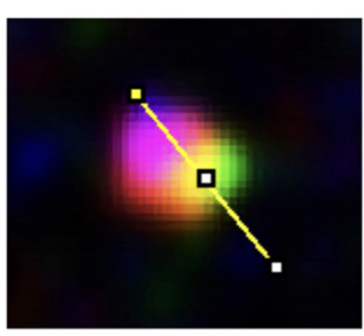

Syn C1q PSD-95

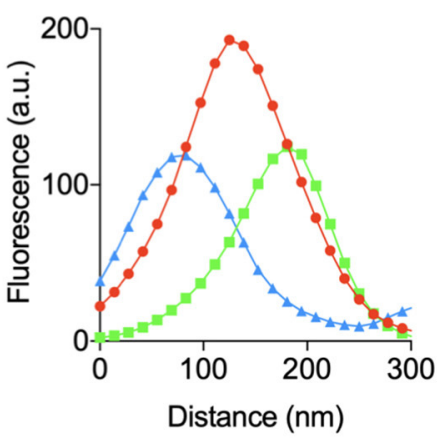

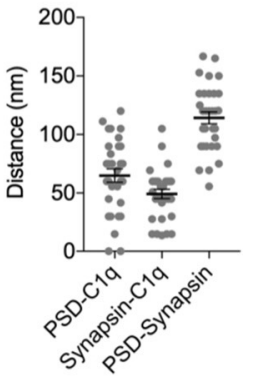

FIGURE 2 | Complement activity at the synapse in the brain of AD tauopathy mice. (A) Timeline for Alzheimer's Disease signs and symptoms to develop in P301S mouse. This mouse is analogous to a hereditary form of AD with a mutation in the tau gene that is a conversion from proline to serine at amino acid position 301 . Timeline information collected from www.Alzform.org. (B) Measurements taken from micrographs of the synaptic region of the P301S mouse hippocampal CA1 region where neuronal structure is disrupted, at nine months. Data from Dejanovic et al. (2018) with permission. Fluorescence recordings from Synapsin at the presynaptic membrane, C1q, and PSD95 at the post-synaptic membrane. Analogous samples from the hippocampal CA1 region of mice without the P301S addition showed C1q staining that was barely detectable, indicating that the C1q location and increased density was due to the AD like pathology in the P301S mice.

et al., 2010; Allen et al., 2015; Kunkle et al., 2019). CR1 acts as a cofactor to Factor I to cleave $\mathrm{C} 3 \mathrm{~b}$ that is on or near to the cell surface of a host cell. This $\mathrm{C} 3 \mathrm{~b}$ can be diffusing $\mathrm{C} 3 \mathrm{~b}$ or $\mathrm{C} 3 \mathrm{~b}$ that is covalently attached to a cell surface moiety. C3b is inactivated and made Convertase incompetent by conversion to iC3b (Figure 5). Thus, CR1 serves to limit the extent of complement activity by the prevention of $\mathrm{C} 3 \mathrm{~b}$ binding to nearby self-cells so they are not tagged for immune clearance. We hypothesize that mutations in CR1 handicap its ability to deactivate $\mathrm{C} 3 \mathrm{~b}$, and the end result is loss of protection to essential brain cells from immune-mediated clearance. The normal number of CR1 receptors on a neuron is unknown, but cell surface CR1 has been characterized on blood plasma cells: only 100-1200 copies on red blood cells and $\sim 20,00-50,000$ on nucleated cells of the immune system (Martin, 2007), so even a small disruption of CR1 functional capacity or structural stability could have significant deleterious effect. In contrast, a more abundant receptor such as CR3 is present on the cell surface in 100,000-200,000 copies (Abbas et al., 2019).

There are multiple mechanisms to explain how CR1 mutations might lead to the loss of host cell protection. The simplest is decreased stability in the mutant protein that results in reduced expression or functionality of CR1 on the cell surface. Normal CR1 moves throughout the membrane and patrols the cell surface (Petty et al., 1980). There may be poor tolerance for a mutant CR1 with limited mobility or decreased cell surface density, resulting in $\mathrm{C} 3 \mathrm{~b}$ levels that are unchecked by inactivation to $\mathrm{iC} 3 \mathrm{~b}$ and cell - surface removal. Point mutations of CR1 associated with the Knops blood group are known to confer increased risk for AD (Sandri et al., 2017) so the concept is within reason. These mutations fall in clusters near the membrane surface (Figure 4). The structural requirements within this region are particularly strict without much room for amino acid side chain variation (the mutations in Figure 4 are each quite conservative). This may relate to interactions with the membrane, ligands, or specific parameters in folding or trafficking that prevent a stable cell surface receptor. The associated risk for $\mathrm{AD}$ is small, and these mutations do not account for the increased frequency that is reported in genome wide association studies (GWAS) for AD risk (Lambert et al., 2009; Jun et al., 2010; Allen et al., 2015; Kunkle et al., 2019).

A CR1 mutant that carries significant $\mathrm{AD}$ risk (two-fold increase) contains a seven Sushi domain insertion (11-17) and an extra C3b binding site. We will refer to this mutant as CR1+7S 1 . $\mathrm{CR} 1+7 \mathrm{~S}$ is present in $\sim 10 \%$ of the general population (Brouwers et al., 2012; Hazrati et al., 2012; Almedia et al., 2018), and, under laboratory conditions, has increased affinity for C3b (Fonseca et al., 2016). Perkins et al. found that C3b dimers bind to CR1 with increased affinity, and that dimers and higher multimers of C3b may form in the presence of Zinc (Nan et al., 2013). Prior to the report from the Perkins laboratory, C3b dimers formed from oxidation reactions were known and studied. Elevated Zinc levels

\footnotetext{
${ }^{1}$ In the literature, this mutant is often denoted as CR1-S or CR1*2.
} 


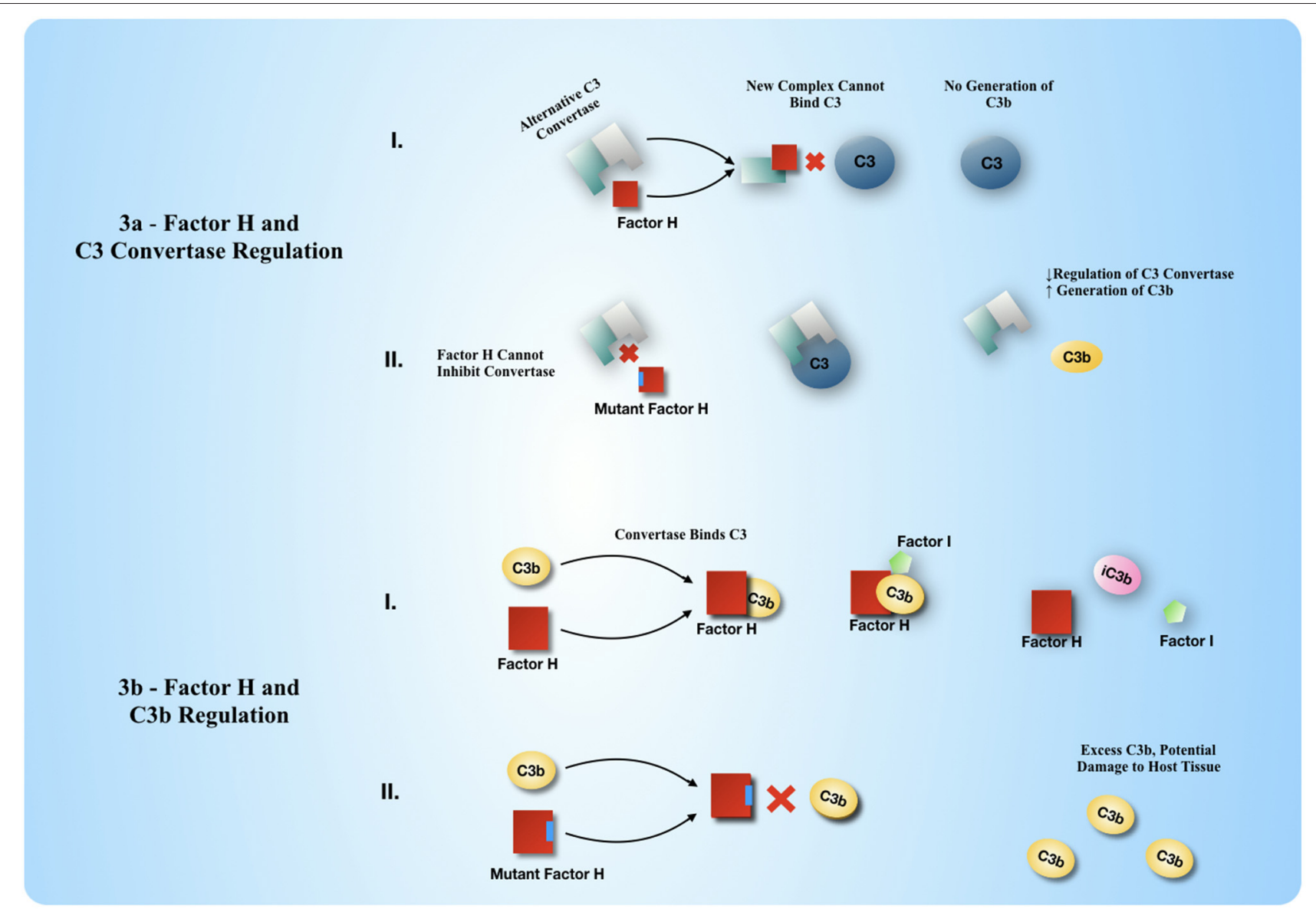

FIGURE 3 | Factor $\mathrm{H}$ regulates the generation of $\mathrm{C} 3 \mathrm{~b}$ and the inactivation of $\mathrm{C} 3 \mathrm{~b}$. (a) Factor $\mathrm{H}$ regulates the generation of $\mathrm{C} 3 \mathrm{~b}$ by active disassembly of the $\mathrm{C} 3$ convertase enzyme. Factor $\mathrm{H}$ displaces the $\mathrm{Bb}$ binding partner to $\mathrm{C} 3 \mathrm{~b}$ to make a new complex with $\mathrm{C} 3 \mathrm{~b}$ that is Factor $\mathrm{H}$ : $\mathrm{C} 3 \mathrm{~b}$, hence ceasing further generation of $\mathrm{C} 3 \mathrm{~b}$. (b) Factor $\mathrm{H}$ regulates the level of $\mathrm{C} 3 \mathrm{~b}$ by participating in further enzymatic degradation of $\mathrm{C} 3 \mathrm{~b}$ to iC3b and other smaller protein fragments. Factor $\mathrm{H}$ acts as a cofactor to Factor I to bring C3b and Factor I together so that factor I may degrade C3b further through proteolysis. iC3b and smaller fragments of C3 can no longer be a part of any C3 convertase assembly, either on a cell surface or as a soluble enzyme in solution.

and an oxidative environment are known factors in $\mathrm{AD}$ (Yan et al., 2013; Bhat et al., 2015; Adlard and Bush, 2018; Zsolt et al., 2020), so C3b dimers are an expected feature of complement biology under the stressful conditions that characterize early neurodegeneration. Should a C3b dimer bind CR1+7S, it may well-bind with greater affinity than $\mathrm{C} 3 \mathrm{~b}$ in the traditional CR1: $\mathrm{C} 3 \mathrm{~b}$ complex. The original purpose to inactivate $\mathrm{C} 3 \mathrm{~b}$ and remove it from the cell surface by internalization may then be defeated. CR1 is known to respond differently depending on the ligand that is bound to it (Java et al., 2015). While C3b or iC3b-bound CR1 is internalized, CR1 bound to C3b that is itself bound to immune complexes is not internalized. Consequently, this complex remains on the cell-surface as an opsonization marker. Cell surface $\mathrm{C} 3 \mathrm{~b}$ or iC3b provide an "EAT ME" opsonization marker on the host self-cell which expresses the CR1 for its own protection. If the complex of a $\mathrm{C} 3 \mathrm{~b}$ dimer and $\mathrm{CR} 1+7 \mathrm{~S}$ is not internalized, the complex would then errantly tag a host cell for immune-mediated destruction. This highlights a clear mechanism for potential neurodegeneration (Figure 5).
Existing experimental evidence fits well with this concept. The Rogaeva and Broeckhoven laboratories took human tissue samples with and without the 7-Sushi CR1 insertion and analyzed them for CR1 and the intracellular protein ERGIC-53 (Hazrati et al., 2012). Neurons with a 30-Sushi domain CR1 ${ }^{+}$showed a fusiform architecture and co-localization of CR1 with ERGIC53 , indicating normal recycling events for Type 1 membrane proteins such as CR1. In the $\mathrm{AD}$ tissue samples, $\mathrm{C} 3$ was identified in a diffuse pattern within the neurons as well as on amyloid and tangle aggregates. The 37-Sushi domain CR1 ${ }^{+}$ neurons were found to have a vesicular pattern, without ERGIC53 colocalization or C3 staining in the same neurons, even though C3 on amyloid and tangles was noted. The vesicular pattern was considered to be a lysosomal location for the larger CR1 receptor. We interpret this finding as soft support for the outcome that the larger CR1 molecules endure the fate of phagocytoses by microglia rather than internalization, since it is expected that the 37-Sushi CR1 with an additional C3b binding site retains C3b binding capacity. As expected, both CR1 

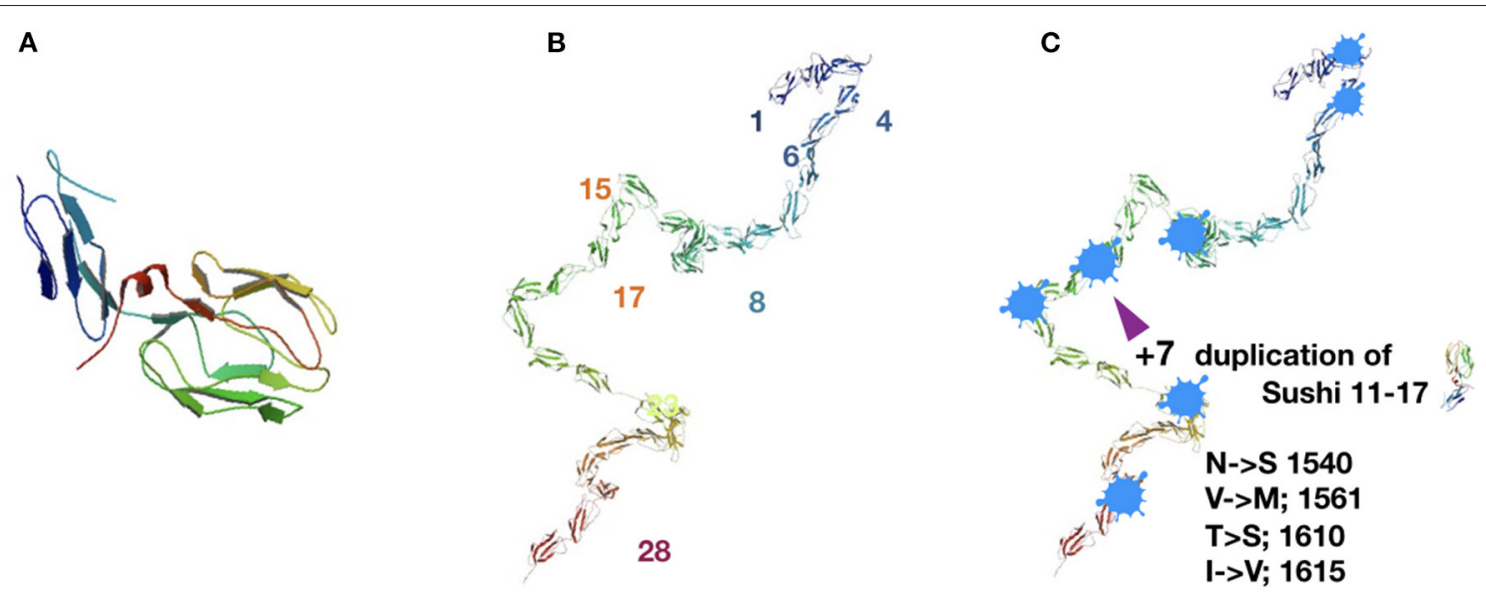

FIGURE 4 | Complement receptor 1 biology with the basic Sushi subunit domain repeat and major and minor alleles of the gene. (A) Single Sushi domain composed of $\sim 60$ amino acids in beta sheet array, two stranded beta sheet facing three strand beta sheet, anti-parallel alignment. Major allele (left) in $83 \%$ of the population. Structure is an extracellular domain of 30 consecutive Sushi domains. Structure PDB 2Q7S, from the laboratory of SJ Perkins at UCL (Furtado et al., 2008). (B) Minor allele (right) in 11\% of the population. The transmembrane domain (not shown) and basic Sushi domain subunit are unchanged. There is a seven Sushi repeat of Sushi domains 11-17, that is located directly adjacent to the original location of the duplicated Sushi domains. The binding site for C3b is located at domains 15-17, so this repeated segment of Sushi domains 11-17 includes a second binding site for C3b. (C) Inkblot; regions of predicted intrinsic disorder within the CR1 amino acid sequence. These are short regions of amino acid repeats or regions mixed with charged amino acids and hydrophobic amino acids in close proximity that create ambiguity about preference for hydrophilic environment or hydrophobic surroundings instead. Prediction programs used were: PONDR developed by Romero, Li, Dunker, Obradovic and Garner, www.pondr.com, described in Xue et al. (2010). IUPRED, www.iupred2a.elite.hu, described in Dosztányi et al. (2005).

receptors have increased expression in the $\mathrm{AD}$ tissues. However, the $\mathrm{CR} 1 / \mathrm{CR} 1+7 \mathrm{~S}$ ratio $(\sim 4.5: 1$, as predicted from the relative prevalence for these two genes, and confirmed in this study) is not maintained, with a larger AD-related increase found for the 37-Sushi CR1 rather than the 30-Sushi CR1 (AD ratio 2 CR1:1 $\mathrm{CR}+7 \mathrm{~S}$ ), for an unknown reason. We suggest this observation might be followed with further molecular dissection of these cells to further understand what complexes are present and what different cellular processes are involved.

\section{The CR1+7S Variant May Complex With Additional Binding Partners Which Influence the Risk of Alzheimer's Disease}

In this section, we will outline a structure-derived model which shows how such a cell surface CR1+7S might attract additional binding partners which influence $\mathrm{AD}$ risk. It is long-established that CR1: C3b: Factor I briefly form a trimeric association for the inactivation of $\mathrm{C} 3 \mathrm{~b}$. We suggest the $\mathrm{CR} 1+7 \mathrm{~S}$ variant with bound $\mathrm{C} 3 \mathrm{~b}$ dimer $\left(\mathrm{C}_{3} \mathrm{~b}_{2}\right)$ could form a more stable association of CR1: C3b: C3b: factor I, with factor I retained in complex based on an altered kinetic profile for this reaction. This stable complex is rich in complex protein structure and may provide a scaffold for a larger protein assembly.

The first proposed binding partner is ApoE, which fits nicely with findings from population-level data. As already mentioned, CR1 is among the strongest known AD risk factors. Similarly, the $\varepsilon 4$ allele of ApoE is the highest risk gene for sporadic $\mathrm{AD}$. The genes for ApoE and CR1+7S both confer AD risk separately. When the genes are present together, however, the risk is increased beyond what would be expected if the genes were operating as $\mathrm{AD}$ risk factors independently of each other. This implies an interaction between CR1 and ApoE. Our complex suggests a mechanism by which this may happen. The Factor I structure includes two LDL receptor A type domains, and ApoE is capable of binding this type of domain (Yamamoto et al., 2008; Guttman et al., 2010; Nilsson et al., 2011). The resulting complex features two major AD risk factors in close proximity to each other and the site of a potential neurodegenerative process.

The second proposed binding partner is $A \beta$. It is wellestablished that ApoE influences $A \beta$ biology, although the nature of this interaction is not fully understood in molecular terms (Jones et al., 2011; Verghese et al., 2013; Garai et al., 2014; Kanekiyo et al., 2014; Ghosh et al., 2019; Oh et al., 2020). Meticulous research from the Holtzman laboratory details the lack of a direct interaction. Another laboratory, however, reports that the interaction is Zinc dependent, and studies from the Holtzman laboratory do not report Zinc being in their assays. It has been shown that $A \beta$ binds to receptors such as LDLR in the absence of ApoE, and it is known that ApoE facilitates the earliest steps in $\mathrm{A} \beta$ self-association as it forms large aggregates. The influence of ApoE may not be from direct physical contact with A $\beta$ (Cho et al., 2001; Kara et al., 2018;

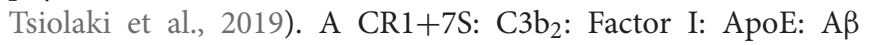
complex is entirely possible from the perspective of biophysical chemistry. Factor I has two LDLR domains. We suggest that ApoE binds one domain, and $\mathrm{A} \beta$ binds ApoE or the second LDLR domain, putting these two molecular entities in close proximity. As described above, we anticipate that Zinc is present under physiological stress conditions, but our model does not demand a molecular preference. 


\section{A - Normal Clearance of C3b via CR1}

I.

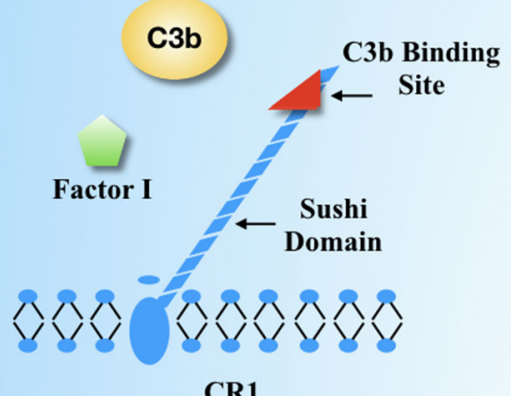

II.

III.
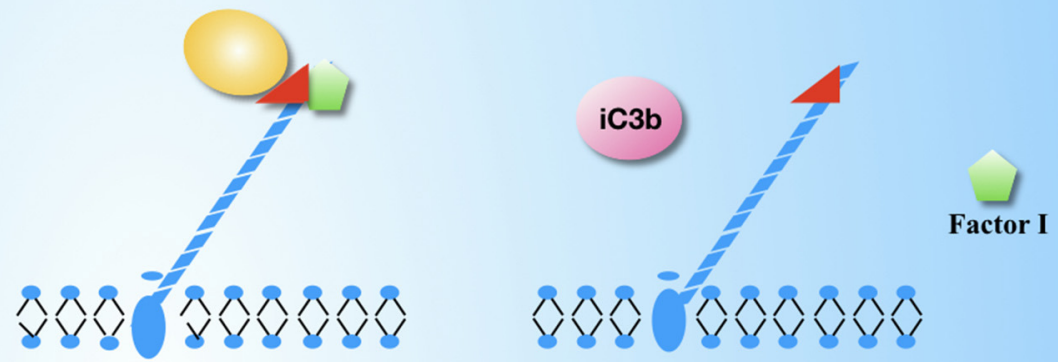

\section{B - Disrupted Clearance of C3b via CR1+7S mutant}

I.

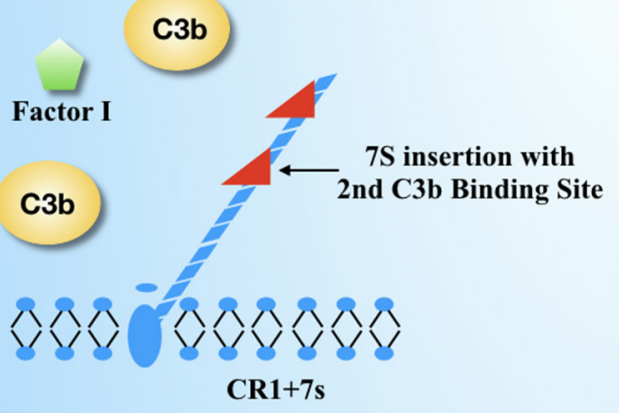

II.

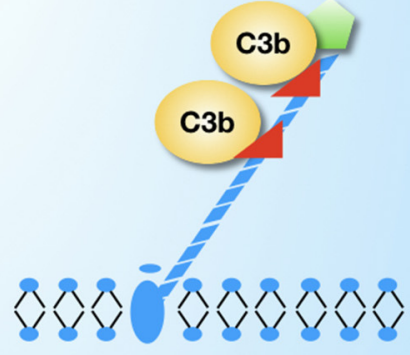

III.

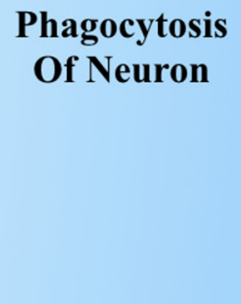

Phagocytosis of Neuron

FIGURE 5 | CR1 Biology with anticipated changes due to duplicated sushi domains in CR1 biology normally and under dysregulation. (A) Under normal circumstances, CR1 acts as a cofactor to Factor I to cleave C3b into iC3b, which is released so that another C3b may be bound and cleaved. (B) Mutant CR1 with a second $\mathrm{C} 3 \mathrm{~b}$ binding site $(\mathrm{CR} 1+7 \mathrm{~S})$ is unable to release the $\mathrm{C} 3 \mathrm{~b}$ dimer because the dimer may bind more tightly. The result is that the cell with this $\mathrm{CR} 1+7 \mathrm{~S}$ on the surface is incorrectly tagged for phagocytosis or endocytosis.

The sequence of the $A \beta$ peptide shown here is littered with a mix of charged and hydrophobic residues and short amino acid repeats, such as $\mathrm{HH}$, FF, and GG: DAEFRHDSGYEVHHQKL VFFAEDVGSNKGAIIGLMVGGVVIA.

This protein region is ambiguously structured before enzymatic cleavage from APP. However, once it is aggregated into amyloid, it is a highly structured $\beta$-sheet predominant sequence. Selected regions of the Sushi domains in $\mathrm{CR} 1^{2}$ are also ambiguous with respect to secondary structure, and it has been proposed that these regions of intrinsic disorder can associate

\footnotetext{
${ }^{2}$ This mutation has a new Sushi-Sushi junction that is Sushi17 - Sushi 11 when the tandem duplication is created. Furthermore, if the CR1 amino acid sequence is examined by programs that predict intrinsic disorder in protein structure (Unipred, Pondr), the N-terminal amino acids in the region of the $\sim 15$ th-20th amino acids are predicted to have intrinsic disorder in a selected number of the Sushi domains meaning that the structure is dynamically unstable and prone to association with like regions in other domains or other proteins.
}

with other labile regions of similar ambiguous structure. These regions marked in Figure $\mathbf{4 C}$ are located at or near the bends in the CR1 atomic structure. One such segment is the bridge between Sushi 15 and Sushi 16. This region is within the C3b binding site and it is found in the repeated domains for this CR1 variant as well. This particular intermolecular interaction between two protein strains with intrinsic disorder is described as a "gel" where the interactions between the participating protein segments resemble the sticky interactions of two pieces of Velcro tape. This is because the interaction is strengthened by hydrophobic and electrostatic forces, but still reversible if the forces are counteracted.

If we focus on these Sushi domain elements that are intrinsically disordered to ask what role they might play, two prospects become apparent. First, these regions are analogous to the disordered Sushi domain in $\mathrm{GABA}_{\mathrm{B}} / \mathrm{a} 2$ receptors that bind APP (Dinamarca et al., 2019; Rice et al., 2019), so APP may bind to this location. The binding site on APP itself 
has significant intrinsic disorder, ${ }^{2}$ in keeping with the nature of protein - protein association (Molliex et al., 2015; Banani et al., 2017; Hughes et al., 2018; Franzmann and Alberti, 2019) in this discussion. Two, monomeric or oligomeric $A \beta$ may interact with these same regions of the CR1 receptor. $A \beta$, at the level of monomer or oligomer, is not yet a firmly and irrevocably stack of $\beta$-strands at this point in the process of self-association and the gel-like interaction is in keeping with a dynamic folding intermediate in transition. It is quite possible that this is an environment that is permissive for amyloid formation but only when factors such as $A \beta$ concentration and solution conditions are favorable for this event. We suggest that this type of complex would provide a depot of soluble $A \beta$ peptide still in reversible equilibrium, yet amyloidogenic under favorable conditions.

To put these processes in the simplest possible terms, consider an analogy: amyloid and the interstitial fluid/CSF compartments are like the oil and vinegar of a basic salad dressing. The oil and vinegar are not miscible except to the smallest extent. Something like a Caesar dressing is homogenous due to the presence of an emulsifying agent, which in our analogy is the ApoE: CR1 complex with the lipids of $A p o E$ and the regions of both $C R 1$ and $A \beta$ with intrinsic disorder forming a gel-like interaction. This dynamic arrangement is metastable until perturbations, such as increased $\mathrm{A} \beta$ concentration, provide an alternative arrangement with greater stability.

We have detailed the mechanics of this binding process in detail because such a complex would imply a potential explanation for an anomaly in clinical data (Schjeide et al., 2011; Brouwers et al., 2012; Thambisetty et al., 2013). Specifically, a complex of CR1+7S: ApoE: $\mathrm{A} \beta$ could resolve the apparent paradox of why patients with the CR1+7S variant show completely opposite amyloid distributions compared to $\mathrm{AD}$ patients, yet still exhibit increased AD risk. APP is cleaved to soluble $A \beta_{1-42}$, which is an intermediate between APP and amyloid aggregate formation. Chemically, $A \beta_{1-42}$ is in dynamic equilibrium between the CNS interstitial fluid and the cerebrospinal fluid (CSF). In $\mathrm{AD}$ patients, the $\mathrm{A} \beta_{1-42}$ becomes insoluble, creating amyloid plaques and altering the chemical equilibrium by the removal of soluble $A \beta_{1-42}$. The resultant clinical finding for $\mathrm{AD}$ patients is high amyloid in the CNS and low $A \beta_{1-42}$ in the CSF due to the redistribution of $A \beta_{1-42}$ into amyloid. For people with the CR1+7S allele, however, they show the unusual finding of lower amyloid burden (by amyloid-PET scan) and a higher concentration of $A \beta_{1-42}$ in the CSF $(\sim 20 \%)$, yet still demonstrate increased $\mathrm{AD}$ risk. If $\mathrm{A} \beta$ binds $A p o E$ : $\mathrm{CR} 1+7 \mathrm{~S}$, this provides a depot for $A \beta$ that will continue to participate in the chemical equilibrium (Figure 6). Therefore, the $A \beta$ : CR1+7S complex would explain the limited plaque formation and higher $\left[\mathrm{A} \beta_{1-42}\right]$ in the CSF relative to $\mathrm{AD}$ patients, while still enabling destruction of host CNS tissue via C3b retention on host cell surface.

In sum, through the nuts and bolts of molecular recognition, it is plausible to conceive a mega-complex containing CR1+7S: $\mathrm{C}_{3} \mathrm{~b}_{2}$ : Factor I: ApoE: A $\beta$ (Figure 7). This is the complex we propose; however, the CR1 is "shown" in the crystallographic image as factor $\mathrm{H}$, because that is the published crystal structure for a ternary complex between an RCA protein, C3b and Factor I. Additionally, in the same figure, we show separate crystal structures for both a factor $\mathrm{H}$ : C3b complex and a CR1: C3b complex to show how greatly analogous these two structures are, due to the common domain arrangements of the RCA family proteins. We anticipate that the larger complex may be greatly analogous as well, with the CR1 domains simply replacing the factor $\mathrm{H}$ domains in the proposed complex.

What potential clues does a CR1+7S: $\mathrm{C}_{3} \mathrm{~b}_{2}$ : Factor I: ApoE: $A \beta$ megacomplex give us about the disease process? Similar to detectives being able to place two high-profile suspects at the scene of the crime together, the significance of this complex is that $\mathrm{ApoE}$ and $\mathrm{CR} 1$, both strong $\mathrm{AD}$ risk factors, are now found together in a situation where neurodegenerative processes are possible. Our model is hypothetical, but this constellation of findings is chemically plausible and sits at the intersection of explaining several clinical findings in AD. Additionally, it nests nicely with two discussions of this phenomenon already in the literature: the "vanishing" amyloid by Gandy et al. (2013) and a hypothesized sequential relationship between C3, ApoE, amyloid, and tau (Bonham et al., 2016). Furthermore, this hypothesis is testable by straightforward methods.

\section{Other Considerations: Cell Surface Sialic Acid}

Though not formally considered a component of the complement pathway, sialic acid is noteworthy as a renewed area of scientific interest that fits the theme of complement dysregulation. Sialic acid is involved in regulating complement activity and, in the brain, microglia activity. Sialic acid offers a sanctuary for soluble RCA proteins such as Factor $\mathrm{H}$ to dock on the membrane surface. This provides a high local concentration of soluble RCA protein in a conformationally adapted form to be at the ready for cell surface complement regulation (Ferreira et al., 2010; Schmidt et al., 2018). In this way, sialic acid contributes to timely regulation of complement activity in the periphery when all complement components other than the cell bound RCA proteins are soluble and found in $\sim 3 \mathrm{~L}$ of blood plasma, due to local concentration effects.

It is not clear that the value is the same in the tightly packed space of the CNS, where there may be an emphasis on local complement synthesis instead (Blaum et al., 2015). Microglia contain surface sialic acid and this moiety is tightly regulated. It has been shown that sialic acid can attenuate the extent of inflammatory damage inflicted by microglia involvement (Griciuc et al., 2013; Miles et al., 2019; Yang et al., 2019; Puigdellivol et al., 2020). If sialic acid is abundant, microglia are not activated toward phagocytosis. In contrast, if the sialic acid has been enzymatically removed, activated microglia aggressively phagocytose. This activation is controlled by microglia cell surface receptor $\mathrm{CD} 33$-also a risk gene for $\mathrm{AD}$-and is an early step in the recruitment of microglia from routine surveillance to active engulfment of proximal matter. These features imply a concept for immune dysregulation via sialic acid, and this is an 


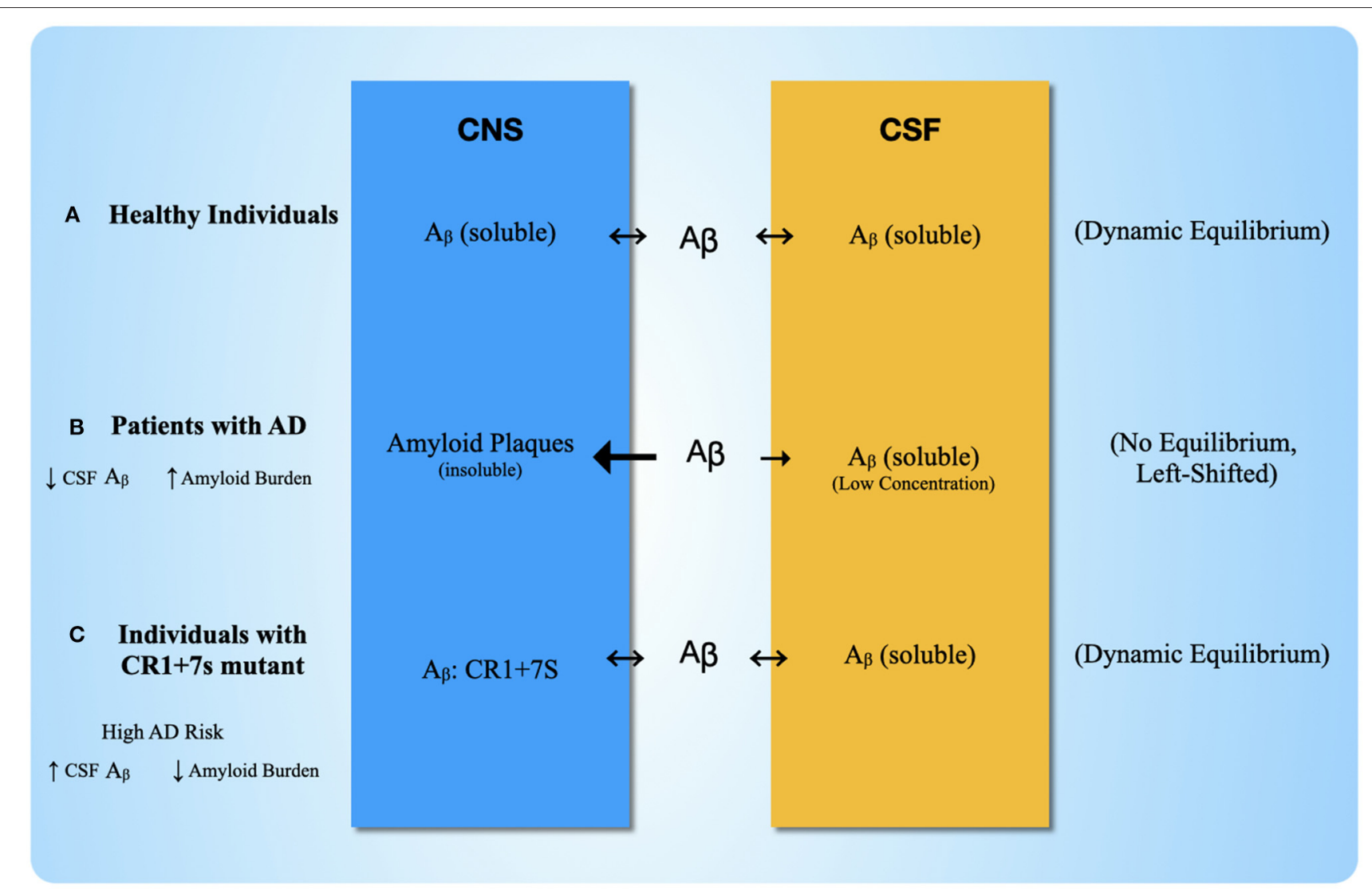

FIGURE 6 | Plausible Explanation for Anomalous Clinical Data with CR1 with seven Sushi Duplication Chemical equilibrium for A $\beta$ in three different scenarios. (A) In Scenario one, healthy individuals show a balanced chemical equilibrium, where A $\beta$ moves into both the CNS extracellular space and the CSF at equal rates and remains soluble. (B) Scenario two shows the disruptions that occur to the equilibrium in AD patients. The A $\beta$ in the CNS becomes insoluble in amyloid plaques, which shifts the equilibrium in favor of plaque formation in the CNS. The result is reduced levels of A $\beta$ in the CSF. (C) Scenario three shows the equilibrium for individuals with the $C R 1+7$ s mutant. $A \beta$ is able to bind CR1+7S, which serves as a depot for $A \beta$ accumulation in the CNS but does not result in plaque formation, allowing continued equilibrium of $A \beta$ into the CSF. Therefore, for those with the CR1+7S mutant, A $\beta$ levels in the CSF will appear "normal," but there is still an increased risk for neurodegeneration via the extra C3b binding site.

active area of investigation as a CNS therapeutic target. However, the jury is still out on the magnitude of effect such a process might have. For instance, neurons have a limited amount of surface sialic acid and this amount is not altered in AD (Griciuc et al., 2013). We believe this cell signaling dynamic merits further study, but we estimate that the impact to intact neuronal circuitry might be less than other changes discussed here. Thus, in our model, we focus on direct factors that impact synaptic integrity.

\section{OVERWHELMED C1-INHIBITOR LEADS TO OVERACTIVE COMPLEMENT}

\section{At What Level Is C1-INH "Overwhelmed?"}

The enzymes of Complement $\mathrm{C} 1$ are active for only a short time before they are irreversibly inhibited by $\mathrm{C} 1$ Inhibitor $(\mathrm{C} 1-$ INH), which circulates freely in biological fluids (Ziccardi and Cooper, 1979; Ziccardi, 1981, 1982; Windfuhr et al., 2005). Upon recognition of an activated C1 enzyme, C1-INH covalently attaches to the active site, preventing further activity of $\mathrm{C} 1$ and, consequently, the entire pathway. C1-INH activity is stoichiometric: one C1-INH molecule is used for each and every molecule of enzyme that is blocked.

C1-INH has multiple targets other than C1. Most significant for this discussion are enzymes of the contact activation system: kallikrein, Factor XI and Factor XII (Davis et al., 2008; Conway, 2015; Yang et al., 2016). The contact activation system is a four-step pathway that promotes blood coagulation, and there are conditions where both classical complement and contact pathway activation are taking place at the same time. Under these circumstances, C1-INH availability may become a factor in adequate regulation for cessation of enzyme activity. This concept is clearly illustrated by hereditary angioneurotic edema (HAE, specifically HAE Type I, HAE Type III), where a single dysfunctional C1-INH allele (resulting in depleted C1INH levels) culminates in potentially life-threatening levels of vasopermeability (Späth et al., 1984; Cugno et al., 2009; Hack et al., 2012; Schmaier, 2019; Kajdacsi et al., 2020).

The average C1-INH plasma level in $\mathrm{HAE}$ is $~ 40 \% \%$ normal (Yang et al., 2016; Castellano et al., 2018; Cicardi and Zuraw, 2018; De Maat et al., 2018), yet this is sufficient to provide normal 


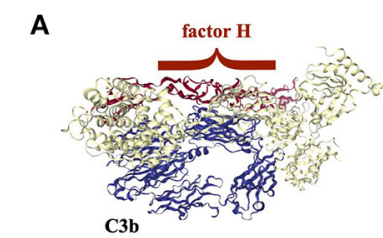

B

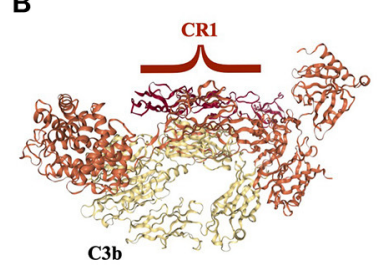

c

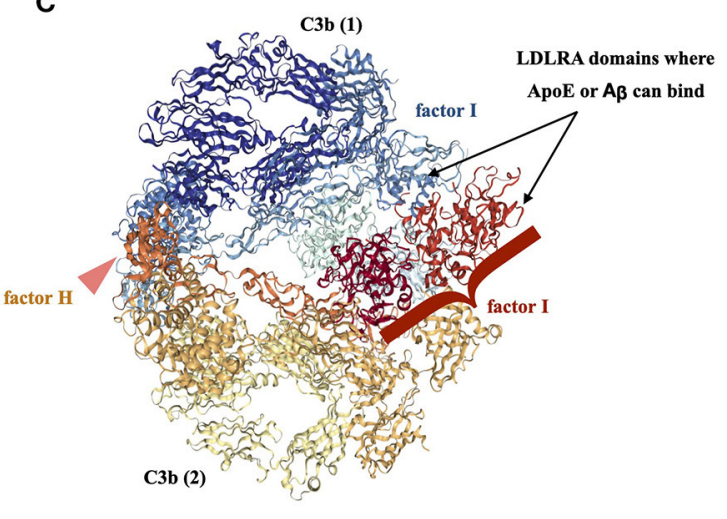

D

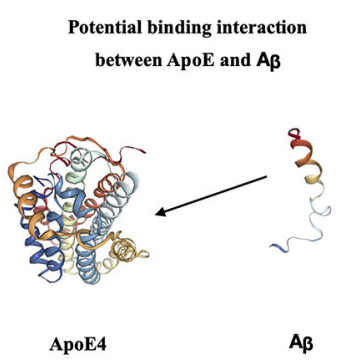

FIGURE 7 | Proposed complex of CR1+7S with Additional Plasma Factors Associated with AD. Crystallographic structures from Protein Data Bank for selected RCA proteins in complex with Complement C3b. Original source for the crystallographic structures, Piet Gros laboratory (Wu et al., 2009; Forneris et al., 2016; Xue et al., 2016). These structures are used as a basis to suggest a macromolecular complex of the composition: CR1+7S: C3b: C3b: CR1+7S: ApoE. (A) Factor H: C3b complex; PDB structure, 2W11. This is a structure of the tub-like C3b structure in cream and navy, and the extended paddle-like structure of the four Sushi domains of factor $\mathrm{H}$ that bind to $\mathrm{C} 3 \mathrm{~b}$ resting on the lip of the tub, in brick red. (B) Complement Receptor 1: C3b complex, PDB structure 5FO9. This is a structure of the tub-like C3b structure in gold, and burnt orange, with the extended paddle-like structure of the four Sushi domains of Complement Receptor 1 that bind to C3b resting on the lip of the tub, in brick red. A comparison of the two C3b complexes where the binding partner is an RCA protein domain of consecutive Sushi domains yields many similarities. If one uses the base of the structure where there is a circular alpha helical tunnel as an orientation point, it can be seen that the C3b portion of the structures are similar to one another in pattern with similar layers of protein secondary structure. The upper surface of C3b is similar in each case and the Sushi domains of the RCA protein nestle within the middle of the structure in a nearly linear array of Sushi domains. (C) Factor H: C3b: Factor I complex; 5032. This is a structure of two C3b domains, one in the lower half of the structure that is oriented analogously to the C3b subunits in 5a and 5b, colors yellow and gold, and a second C3b subunit in the upper half of the structure that is inverted, colors navy, slate blue. Within the middle of the C3b "sandwich" are both a Factor $\mathrm{H}$ Sushi string in burnt orange, and a Factor I subunit, in aqua and two shades of red. An analogous ternary structure for CR1, C3b, and factor I does not exist, but we believe that such a structure would be similar to this one, based on the extensive similarity of the Factor $\mathrm{H}$ : C3b and CR1: C3b structures that can be observed in (A,B). We contend that this structure is informative about the arrangement of a mega complex that might include A $\beta$ or APP binding to the Sushi domains of CR1, quite possibly at the newly formed Sushi - Sushi interfaces made due to the seven Sushi duplication and insertion, and Apoe binding to the LDLR-A domains of factor I, shown in the two shades of red in (C). (D) ApoE and A $\beta$ are two additional binding partners that may bind to the complex via the LDLR domains in factor I. Each of these factors may bind to an LDLR domain, or the complex of ApoE $\mid A \beta$ may bind to an LDLR domain.

TABLE 1 | Stoichiometry of C1-inhibitor and the enzymes it inhibits.

\begin{tabular}{|c|c|c|c|c|c|c|c|c|c|}
\hline \multirow{2}{*}{\multicolumn{2}{|c|}{ C1-INH }} & \multicolumn{8}{|c|}{ Enzymes Inhibited by C1-INH } \\
\hline & & \multicolumn{2}{|c|}{ Classical pathway } & \multicolumn{3}{|c|}{ Contact pathway } & \multicolumn{3}{|c|}{ Lectin pathway } \\
\hline Resting & Acute Phase & C1r & C1s & Kallikrein & Factor XI & Factor XII & MASP I & MASP \| & MASP III \\
\hline $0.16 \mu \mathrm{mole} / \mathrm{L}$ & $0.35 \mu \mathrm{mole} / \mathrm{L}$ & $0.2 \mu \mathrm{mole} / \mathrm{L}$ & $0.2 \mu \mathrm{mole} / \mathrm{L}$ & $0.1 \mu \mathrm{mole} / \mathrm{L}$ & $30 \mathrm{~nm} / \mathrm{L}$ & $0.5 \mu \mathrm{mole} / \mathrm{L}$ & $70 \mathrm{~nm} / \mathrm{L}$ & $5 \mathrm{~nm} / \mathrm{L}$ & $0.2 \mu \mathrm{mole} / \mathrm{L}$ \\
\hline \multicolumn{2}{|c|}{ Total: $0.16-0.35 \mu$ mole/L } & \multicolumn{2}{|c|}{ Total: $0.4 \mu \mathrm{mole} / \mathrm{L}$} & \multicolumn{3}{|c|}{ Total: $0.63 \mu \mathrm{mole} / \mathrm{L}$} & \multicolumn{3}{|c|}{ Total: $0.275 \mu \mathrm{mole} / \mathrm{L}$} \\
\hline \multicolumn{2}{|c|}{ 0.16-0.35 $\mu \mathrm{mole} / \mathrm{L}$ (Total C1-INH) } & \multicolumn{8}{|c|}{$1.305 \mu \mathrm{mole} / \mathrm{L}$ (Total of all inhibited enzymes) } \\
\hline
\end{tabular}

immune function on most days. During an attack of angioedema, the $\mathrm{C} 1$-INH levels drop to 10-20\% normal through consumption of the C1-INH in its role to inhibit plasma serine proteases. Table 1 lists the normal levels of all plasma serine proteases that are inhibited by C1-INH. C1-INH is not at molar excess to any of the pathways it inhibits. Since inhibition is by formation of a 1:1 complex between $\mathrm{C} 1-\mathrm{INH}$ and the protease, the $\mathrm{C} 1-\mathrm{INH}$ protein is insufficient to inhibit all of the enzymes in any one of the pathways, particularly the contact activation cluster of enzymes. That said, the pertinent biology for both complement and contact activation is local activation and inhibition over a small anatomical area at any one time, for pathogen clearance or localized vasopermeability and these events occur as necessary. Using HAE as a blueprint, we can establish a lower limit for effective C1-INH concentration at $\sim 0.06$ umole/L, or $\sim 40 \%$ normal value.

\section{C1 INH Insufficiency in AD}

Lack of complement regulation in $\mathrm{AD}$ has been documented since 1999. The McGeer laboratory (Yasojima et al., 1999) found that $\mathrm{C} 1$-INH was disproportionately distributed in brain areas of active AD. Compared to normal tissue, complement levels were increased to $\sim 3$ times for early pathway components (e.g., C1) and up to 20 times for the cytolytic MAC complex. In contrast, C1-INH levels were only increased by $\sim 2$ times. The previous section showed that $\mathrm{C} 1-\mathrm{INH}$ is sub-stoichiometric to the pathways it inhibits, and this experiment provides a clear picture within $\mathrm{AD}$ where $\mathrm{C} 1-\mathrm{INH}$ levels did not match increased complement activation.

We suggest that AD may have resemblance to an HAE attack in the sense of dysregulation from C1-INH depletion to $<\sim 40 \%$ normal value. In our model, the CNS classical complement cascade participates in its housekeeping role up to the point of 
C1-INH depletion. After that point, dysregulated complement activation and contact pathway activation may be features of $\mathrm{AD}$ due to the unregulated level of activation in both pathways. The concept applies, since neuroinflammation is a major aspect of AD (Späth et al., 1984; Conway, 2015; Yang et al., 2016), as is neurodegeneration, which we propose here may be related to haywire complement activity. Two possible scenarios might lead to C1-INH depletion: (1) a situation of degenerative pathology that overwhelms the clearance capacity for complement, such that what would normally be a brief pulse of complement activity becomes a continuous event over repetitive attempts to clear an insurmountable quantity of unwanted material, and (2) simultaneous activity of complement activation and contact pathway activation.

The first scenario is immanently plausible: this could be as simple as complement becoming overwhelmed by the continuous accumulation of both amyloid and NfT, along with attempts to clear damaged synapses. It is established that complement binds amyloid, NfT, and synapses. Likewise, the progression of pathology in AD is well-documented. Self-association of $A \beta$ fragments into oligomers and fibrils is a necessary, but not sufficient, first step. Next, the hyperphosphorylation of Tau protein is followed by tau aggregation into neurofibrillary tangles. NfT formation tracks in a synchronized manner with cognitive impairment, which is caused by synapse damage and loss, so complement-mediated synapse clearance must begin prior to, or simultaneous with tau pathology. At the inception of mild cognitive impairment, or perhaps just before, these three processes are simultaneously ongoing. Each of these processes involves complement activation and clearance, and thereby, complement regulation by $\mathrm{C} 1-\mathrm{INH}$ and the RCA protein family.

So far, the study of C1-INH in AD has not been approached from this type of mechanistic perspective. It has, however, been investigated as a possible biomarker in several clinical trials on AD. From these reports, we know that C1-INH levels are insufficient at the time of the diagnosis of mild cognitive impairment. This finding is consistent with early complement measurements in $\mathrm{AD}$ where it was reported that the levels of C1-INH did not increase to the same extent as the pathway components, such as $\mathrm{C} 3$ and complement proteins of the membrane attack complex, C5-C9 (Yasojima et al., 1999). Regarding C1-INH reported values at the time of mild cognitive impairment, the study design/methodologies vary and the conclusions are mixed. Three separate studies representing a total of $\sim 500$ patients with mild cognitive impairment or worse clinical picture report a reduced C1INH level to $\sim 60 \%$ normal (Cutler et al., 2008; Muenchhoff et al., 2015; Shen et al., 2017; Singh et al., 2020). Indeed, one of these studies from the Strickland laboratory at The Rockefeller University, discussed below, is a combined study where the biological consequences of $\mathrm{C} 1-\mathrm{INH}$ depletion are documented as well. Other studies simply report C1-INH levels in a panel of putative biomarkers to corroborate with a diagnosis of mild cognitive impairment, where there is a distinct correlation.
At this time, one can only speculate about the fate of the missing 40\% C1-INH. Fortunately, AD patients are not prone to unexpected bouts of edema as the level is not in the HAE crisis range, and it is not expected that there is significant complement or contact activation going on in the periphery. This leads us to the prediction that the C1-INH has been consumed at the BBB or within the CNS. The translocation of C1-INH to the brain has been observed in a C1-INH knockout mouse, strengthening this position (Farfara et al., 2019).

The second scenario-simultaneous activation of the CCP and contact pathways-is verifiable by straightforward research but the question has not been addressed directly. The remainder of this section will explore the current literature supporting this concept.

There is abundant evidence for contact pathway activation in AD (Shibiyama et al., 1999; Bergamschini et al., 2001; Maas et al., 2008; Strickland, 2018). Cleaved factor XII, an indicator of contact activation, has been measured in plasma from $\mathrm{AD}$ patients in separate collections and from separate laboratories (Zamolodchikov et al., 2015; Suidan et al., 2018). Cleaved factor XII has been found in AD plasma to a greater extent than normal plasma from age-matched controls. Additionally, Factor XII KO (by anti-sense technology) mice have been used to evaluate the effect of reduced contact pathway activity on AD. These mice showed less microglia activation, reduced neuron damage, reduced cognitive impairment, and less overall brain damage (Chen et al., 2017). Bradykinin is also an indicator of contact pathway activation. In the periphery, Cicardi et al. showed that the life-threatening inflammation of HAE is driven by excess bradykinin levels (Curd and Prograis, 1980; Nussberger et al., 1998, 1999). In the CNS, Strickland et al. measured plasma clotting times and bradykinin levels (plasma and CSF) in AD patients directly (Bergamschini et al., 2001), finding that the level of bradykinin increased linearly with the severity of cognitive impairment and the AD biomarkers, neurofilament light chain and $A \beta_{1-42}$. This clearly showed a direct relationship between contact activation and the severity of $\mathrm{AD}$. Together, these two studies show that contact pathway activation tracks with harmful inflammation in $\mathrm{HAE}$ and $\mathrm{AD}$, with HAE being a known disease of C1-INH depletion. This reinforce our hypothesis that excess contact activation in $\mathrm{AD}$ is linked to C1INH depletion.

C1-INH KO mice (antisense technology) also show relevant vascular features. A C1-INH KO mouse model was found to have significant immune reactivity, including IL-6 release and induction of nitric oxide synthase, indicating considerable CNS inflammation (Farfara et al., 2019). Moreover, the compromised BBB was accompanied by infiltration of immune reactive cells from the periphery. The fact that C1-INH depletion is linked to BBB compromise lends further support to our model: if there is an occasion where continuous complement and contact pathway activity is ongoing, it is likely at or near the BBB. This is significant because there is a strong correlation between vascular dementia and $\mathrm{AD}$. In some cases, vascular dementia has been shown as a precursor to AD dementia (De la Torre, 2004; Zlokovic, 2011; 
Iadecola, 2013; Kisler et al., 2017), though this is not the universal case.

Compromised integrity of the $\mathrm{BBB}$ is known to be a feature of $\mathrm{AD}$, but at what point in the disease process it is compromised is not fully understood. For carriers of the Apoe 4 allele, deterioration of the BBB occurs earlier (Montagne et al., 2020). A recent study of the timeline from young to aged mice described fundamental changes to the exchange process at the $\mathrm{BBB}$ endothelial cell surface (Yang et al., 2020). In younger animals, exchange of blood components was tightly controlled by receptor-mediated endocytosis via clathrin coated pits. In contrast, older animals showed loss of pericytes and CNS protection in the extraluminal space. These changes were accompanied by a shift to generalized endocytosis with less chemical specificity, such that the BBB was now permeable to a wider range of macromolecules. A proteomebased study of the early cortical lesions in multiple sclerosis found evidence for contact activation, complement activation, and iron dysregulation (Magliozi et al., 2019), so it is quite possible this same constellation is an aspect of early-stage AD as well.

Autopsy samples demonstrate that microvascular compromise with pericyte damage and loss of function is present in AD (Zenaro et al., 2017; Nation et al., 2019). A common condition found in small arteries is cerebral amyloid angiopathy (CAA) (Carriano et al., 2012; Halliday et al., 2016; Hernandez et al., 2019), which is more prevalent in carriers of the Apos4 allele (Hultman et al., 2013). CAA is identified by the presence of amyloid within the walls of small-diameter arteries in the brain, and the amyloid typically is $A \beta$-based but not always $A \beta$-derived. The aggregates are known to activate the complement pathway (Matsuo et al., 2017) and introduce a coagulopathy, likely based on the presence of a consequential irregular surface to the vessel wall. Contact activation is one aspect of the coagulopathy (Nishitsuji et al., 2011), so the only unknown component to our suggestion is iron dysregulation. From the groundbreaking work of Katerina Akassoglou's laboratory, an early, partial list of proteins that enter into the brain parenchyma has been reported from work on MS (Bardehle et al., 2015; Merlini et al., 2019; Akassaglou, 2020). Among these is the clotting protein fibrinogen. With the expectation that there is a certain commonality to early degeneration across several diseases, it is well-worth a similar study in AD. Using an integrated approach that included bioinformatics and mRNA screening of brain samples subjected to oxidative stress, Dr. Akassaglou and colleagues have confirmed the significance of glutathione metabolism in early stages of MS (Mendiola et al., 2020). Glutathione dysregulation is a hallmark of the iron-mediated cell death known as ferroptosis, suggesting the findings concur with the proteomic analysis.

In summary, simultaneous activation of the complement and contact pathways could overwhelm $\mathrm{C} 1-\mathrm{INH}$ to a dangerous level. This idea has not been tested directly; however, the results of several independent studies consistently support the concept of C1-INH as a gatekeeper for immune activity and inflammation. We recommend this as a topic of potentially high-yield investigation. The exciting implication is that, if confirmed that $\mathrm{C} 1-\mathrm{INH}$ depletion is promoting the progression of $\mathrm{AD}, \mathrm{C} 1-\mathrm{INH}$ replacement would be a potential neurotherapeutic agent.

\section{Theoretical Applications for the Ratio of Complement to Inhibitors of Complement}

Within the framework of our model, insufficient or dysregulated complement regulators would influence the amount of excess, "bystander" synaptic pruning from inappropriate complement activity and/or inflammatory processes underway in the CNS. If validated, this concept has potential application to companion biomarkers. The relative values of regulatory molecules (such as C1-INH) and available complement or consumed complement would give a readout about the effective regulation of complement. If the level of complement regulators is withing working range, it can be expected that one is protected by the appropriate level of complement providing protection as part of the innate immune system. If the levels are not appropriate, this finding would provide an alarm for the possible cell and tissue destruction that is ongoing instead.

\section{CSMD PROTEINS ARE PUTATIVE COMPLEMENT CONTROL PROTEINS \\ CSMD1 Sushi Domains 17-21 Mimic C4bp to Limit C3b Formation}

In the brain, the Cub Sushi Multiple Domain (CSMD) proteins are located at the post-synaptic density (PSD), a thickened membrane segment with an assembly of scaffolding molecules that anchor neurotransmitter receptors and participate in the signaling that follows neurotransmitter binding (Kraus et al., 2006; Havik et al., 2011; Steen et al., 2013; Mizukami et al., 2016; Athanasiu et al., 2017; Gutierrez et al., 2019). These CSMD proteins are known loci for disease susceptibility. CSMD1 knock-out (KO) mice have increased anxiety, reduced cognition, and additional mood disturbances (Kraus et al., 2006; Havik et al., 2011; Steen et al., 2013; Athanasiu et al., 2017). CSMD2 is a schizophrenia risk gene and $\mathrm{KO}$ animals have reduced cognition (Havik et al., 2011; Athanasiu et al., 2017; Gutierrez et al., 2019). CSMD3 can be found on dendrites of hippocampal neurons. It is thought to play a role in dendrite development, and CSMD3 overexpression has been correlated to increased branching (Mizukami et al., 2016).

CSMD proteins are putative complement control proteins, based on domain homologies to proteins in the RCA cluster and complement pathway enzymes. The domain arrangement of these proteins is similar to one another and unusual in that the Sushi domains are both interspersed with the CUB domains and in a separate sequential string, similar to the RCA cluster of complement control proteins. In a laboratory evaluation of complement function, a soluble CSMD1-like construct of CUB/Sushi/Sushi12 caused reduced C3b deposition on a cell surface where complement activation was measured (EscuerdoEsparaza et al., 2013). This was explained by the later finding that Sushi domains 17-21 of CSMD1 mimic complement component C4bp (Magdalon et al., 2020), inhibiting the classical C3 convertase in a dose-dependent manner. Therefore, CSMD1 
provides a regulatory stop signal for $\mathrm{C} 3 \mathrm{~b}$ generation and any further clearance from the classical complement pathway. It is located uniquely at the PSD where synaptic pruning might be "in order," but still needs to be carried out in a manner that is carefully regulated.

\section{CSMD Proteins May Participate in a Cell Signaling Complex for Synapse Formation and Dendrite Expansion}

Do the unique CUB/Sushi domains of CSMD proteins have a separate function that is distinct from the regulation of complement activity? It is not known. From the perspective of protein biochemistry, however, the question is certainly worth asking. The string of Sushi domains in these proteins is analogous to the domain arrangement of the RCA proteins. However, none of the RCA proteins have a string of Sushi domains in the alternating CUB | Sushi register that is found in CSMD proteins. The section above presents both structural and functional evidence for CSMD proteins to function as complement control proteins similar to the RCA proteins. The discussion that follows is more speculative: we draw on biophysical relationships to highlight the suggestion of a second CSMD function consistent with the theme of complement biology.

The sequential CUB/Sushi cluster is found in several serine proteases within the complement family (Wallis, 2007; Gaboriaud et al., 2014). The CUB domain is most often an interaction domain, not the enzymatic domain. For many complement enzymes the CUB domain heavy chain creates substrate exclusivity for the generic serine protease active site (Gaboriaud et al., 2014). CUB domains are found in other enzymes as well, such as metalloproteinases and phosphatases (Gaboriaud et al., 2011), both commonly found in cell signaling complexes and membrane remodeling enzymes. Typically, metalloproteinases are membranous enzymes that digest extracellular matrix proteins as one aspect of tissue remodeling and phosphatases participate in cell signaling biology directed at tissue growth. As one example, CUBdomain containing protein 1 (CDCP1) promotes matrix metalloproteinase-9 secretion and degradation of extracellular matrix (Miyazawa et al., 2010).

Sushi domains are found in many proteins as well, many of which are binding partners to the protein portion of proteoglycans on the cell surface and integral to the extracellular matrix (Makou et al., 2015). Going by structural homology and location, we speculate that the CSMD proteins could be part of cell signaling centers involved in the essentials of new synapse formation and possibly dendrite growth and expansion (Figure 8). What might that signal be, and is it related to complement activity? Previous literature is sparse. A recent paper from Molofsky et al. describes crosstalk between the neuron and microglia via neuronal synthesis of IL33 and microglia expression of an IL33 receptor that mediates microglia-driven engulfment of extracellular matrix components (Nguyen et al., 2020). We hypothesize that a CSMD signaling complex might be one aspect of this process to make room for new synapses. Since the PSD is where C1q has been visualized (Dejanovic et al.,
2018; Litvinchuk et al., 2018), it is plausible that C1q or C1 binds to the CSMD complex via a CUB domain(s) to initiate either clearance via traditional complement steps or recovery through a cell signaling mechanism within the CSMD complex. Other models are possible, and the C-terminal section of sequential Sushi domains may be the location of binding partners for another purpose.

Given a putative location of CSMD1 at the PSD, this fits the concept of CSMD proteins acting within a cell-signaling complex directed at synaptic and/or dendritic growth, where inhibition of bystander complement activity would be of paramount importance. This can also be investigated experimentally. As one example, it would be informative to compare synapses and wild type and CSMD KO for synaptic density, dendrite patterns, and factors associated with synapse and dendrite formation such as metalloproteinases and phosphatases. If this hypothesis is born out, CSMD proteins provide an essential biological switch aimed at synaptic retention and synaptic growth, two essential features of robust neuronal circuitry required for learning and memory.

\section{CONCLUSIONS}

We have detailed how perturbations of complement regulation may disrupt neuronal homeostasis within the brain. Combining complement biochemistry with advances in neuroscience, we offer the perspective that complement may be a double-edged sword: improperly regulated, the blade may just as swiftly damage the body it is meant to defend. Regulatory features such as C1Inhibitor have not been explored, and proteins of the RCA cluster have not been viewed in their proper protective role.

Disabled proteins within the RCA cluster, such as Factor $\mathrm{H}$, result in C3b-mediated tissue damage in the periphery. Application of this concept to the CNS is straightforward and merits experimental investigation. While we know the classical complement pathway proceeds up to C3 cleavage within the CNS, complete complement factor analysis is missing and would greatly illuminate this area of biology. The most compelling example is CR1, which is among the strongest $\mathrm{AD}$ risk factors. Some regions of CR1 are intolerant of even minor point mutations, and since very few molecules of CR1 are present on the cell surface, even a small disruption to CR1 function or expression could impact its ability to clear C3b.Additionally, from a protein domain perspective, the CR1 $+7 \mathrm{~S}$ variant not only explains clinical findings for varying levels of amyloid burden, but also provides a mechanism for how CR1 and ApoE may interact with one another at the site of a neurodegenerative process.

C1-Inhibitor suppresses excess activation of complement and contact activation. Should this vital regulator be depleted or overwhelmed, the destructive power of complement is free to be unleashed on the body and brain with devastating effect. This is known beyond doubt in hereditary angioneurotic edema, and we have outlined how this may be a compelling explanation for the neurodegeneration in $\mathrm{AD}$ as well. The exciting consequence of this model is that, if confirmed, C1-INH replacement would be implicated as a viable neurotherapeutic intervention. Moreover, 


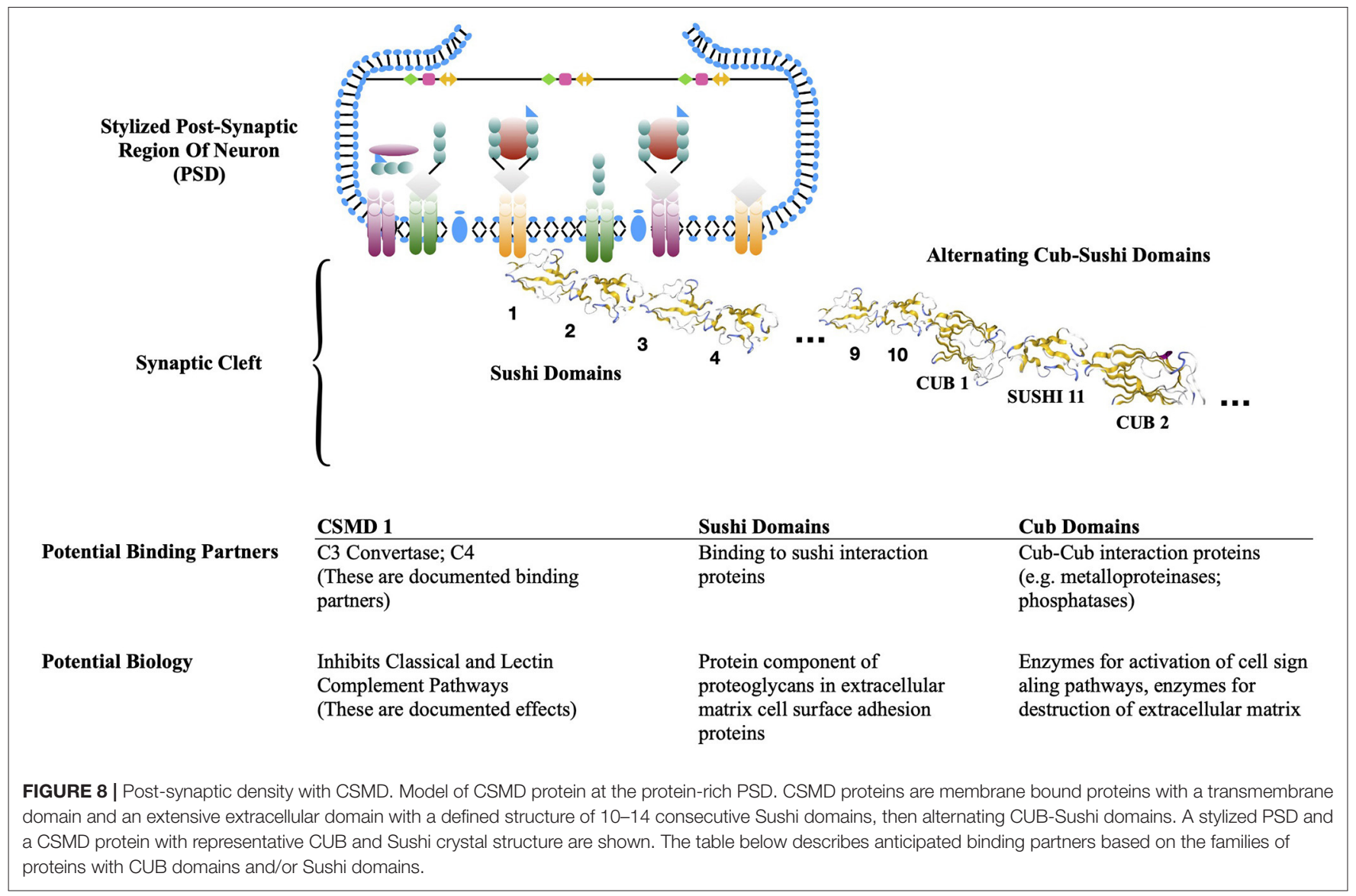

the concept implies measurements of complement inhibitor availability could comprise at least two sets of biomarkers to assess how well-complement regulation is working.

Finally, the CSMD proteins are known loci of disease susceptibility in the brain and their depletion creates behavioral changes in mice. We have outlined how they may function as putative complement control proteins in similar fashion to the RCA family of proteins. Additionally, given their location at the PSD and unique domain composition, we have put forward an intriguing position regarding these proteins as integral features of cell-signaling centers that control synapse retention and new synapse formation and dendrite growth. By structural comparison, metalloproteinases, and phosphatases are possible ligands. This putative function links complement to multiple CNS disease loci and is based on testable biochemical models.

Our model is hypothetical and must be understood as such. We have aimed to illustrate the merit of complement dsyregulation in the CNS as a timely and worthwhile object of study and attempted to provoke new ways of thinking about ageold processes. Furthermore, we have striven to highlight ideas that are testable within the current framework of knowledge, including: (1) the CR1 megacomplex, (2) molecular dissection of cells to understand what complexes are present, (3) complement factor analysis via immunohistochemical studies, (4) the use of complement measurements as companion biomarkers for disease and CNS status, to provide an early picture of neurodegeneration,
(5) the use of complement measurements to evaluate the extent of inflammation, and (6) comparing wild type and CSMD KO synapses for patterns of factors associated with dendritic and synaptic growth. Our major ideas-including the analogy of HAE to C1-INH insufficiency in the CNS, CR1 and apoE as factors in $\mathrm{AD}$, plus Factor $\mathrm{H}$ in ocular and renal disease - are grounded in human studies. In most cases, we limited our use of publications with animal data to literature where the essential points of the manuscript were confirmed with the analysis of relevant human samples.

In sum, regulated complement is an integral aspect of optimal brain function and development, while (as we have argued) dysregulation contributes to disease. Viewing CNS pathology through this lens generates new questions and rich potential for experimental and theoretical progress. Neuro-immunology is in its infancy and complement regulation will be a defining feature as this field comes of age. Regardless of whether the particulars of this model are ultimately confirmed or falsified, understanding the role of complement regulation in the CNSand how regulatory failure may produce disease states-is critical to expanding our study of intractable neurodegenerative conditions such as Alzheimer's. This manuscript is therefore a call to action for research to clarify the transition from normal physiology to pathophysiology that describes the early stages of disease. We believe this will open new diagnostic and therapeutic options for CNS disease. 


\section{DATA AVAILABILITY STATEMENT}

The original contributions presented in the study are included in the article/supplementary material, further inquiries can be directed to the corresponding author/s.

\section{AUTHOR'S NOTE}

We dedicate this article to Marco Cicardi, MD, and Robert David Moir, PhD. Both these excellent scientists left this world too soon, but their quality contributions to medical research are

\section{REFERENCES}

Abbas, A. K., Lichtman, A. H., and Pillai, S. (2019). Basic Immunology: Functions and Disorders of the Immune System. Philidelphia, PA: Elsevier Health Sciences.

Adlard, P. A., and Bush, A. (2018). Metals and AD: how far have we come in the clinic? J. Alzheimer's Dis. 62, 1369-1379. doi: 10.3233/JAD-170662

Akassaglou, K. (2020). The immunology of blood: connecting the dots at the neurovascular interface. Nat. Immunol. 17, 710-712. doi: 10.1038/s41590-020-0671-z

Allen, M., Kachadoorian, M., Carrasquillo, M. M., Karhade, A., Manly, L., Burgess, J. D., et al. (2015). Late-onset Alzheimer disease risk variants mark brain regulatory loci. Neurol. Genetics. 1:e15. doi: 10.1212/NXG.00000000000 00012

Almedia, J. F. F., dos Santos, L. R., Trancozo, M., and dePaula, F. (2018). Updated Meta-analysis of BIN1, CR1, MS4A6a, CLU and ABCA7 Variants in Alzheimer's disease. J. Mole Neurosci. 64, 471-477. doi: 10.1007/s12031-018-1045-y

Alzheimer's Forum Chromosomal Location for AD Risk Genes. Available online at: http://www.alzgene.org/chromo.asp? $c=6$ (accessed August 15, 2020).

Athanasiu, L., Giddauru, S., and Fernandes, C. (2017). A genetic association study of CSMD1 and CSMD2 with cognitive function brain, behavior and immunity. Brain Behav. Immun. 61, 209-216. doi: 10.1016/j.bbi.2016.11.026

Banani, S. F., Lee, H. O., Hyman, A. A., Loughlin, M., Rosen, M. K., Mittag, T., et al. (2017). Biomolecular condensates: organizers of cellular biochemistry. Nat. Rev. Mol. Cell Biol. 18, 285-298. doi: 10.1038/nrm.2017.7

Bardehle, S., Rafalski, V. A., and Akassaglou, K. (2015). Breaking boundaries coagulation and fibrinolysis at the neurovascular interface. Front. Cell Neurosci. 9, 354-360. doi: 10.3389/fncel.2015.00354

Bergamschini, L., Donarini, C., Gobbo, G., Parnetti, L., Gallai, V., DeBouck, C. M., et al. (2001). Activation of complement and contact system in Alzheimer's disease. Mech. Age. Dev. 122, 1971-1983. doi: 10.1016/S0047-6374(01)00311-6

Bhat, A. H., Dar, K. B., Anees, S., Zargar, M. A., Masood, A., Sofi, M. A., et al. (2015). Oxidative stress, mitochondrial dysfunction, and neurodegenerative disease; a mechanistic insight. Biomed. Pharmacother. 74, 101-110. doi: 10.1016/j.biopha.2015.07.025

Blaum, B. S., Hannan, J. P., Herbert, A. P., Kavanagh, D., Uhrin, D., and Stehle, T. (2015). Structural basis for sialic acid-mediated self cognition by complement factor H. Nat. Chem. Biol. 11, 77-82. doi: 10.1038/nchembio.1696

Bohlen, C. J., Friedman, B. A., Dejanovic, B., and Sheng, M. (2019). Microglia in brain development, homeostasis and neurodegeneration. Ann. Rev. Genetics. 53, 263-288. doi: 10.1146/annurev-genet-112618-043515

Bonham, L. W., Desikan, R. S., and Yokoyama, J. S. (2016). The relationship between complement C3, APO 84 , amyloid and Tau in Alzheimer's disease. Acta Neuropathol. Commun. 4, 65-71. doi: 10.1186/s40478-016-0339-y

Boyajyan, A., Khoyetsyan, A., and Chuvushyan, A. (2010). Alternative complement pathway in schizophrenia. Neurochem. Res. 35, 894-898. doi: 10.1007/s11064-010-0126-2

Brouwers, N., Van Cauwenberghe, C. V., Engelorghs, S., Lambert, J. C., Bettens, K., LeBastard, N., et al. (2012). Alzheimer risk associated with a copy number variation in the complement receptor 1 increasing C3b / C4b binding sites. Mol. Psychiatry. 17, 223-233. doi: 10.1038/mp.2011.24 long-lasting. It is up to those who remain to carry their quality legacy forward.

\section{AUTHOR CONTRIBUTIONS}

CS conceived the concept of immune dysregulation and linkage between $\mathrm{HAE}$ and $\mathrm{AD}$. NP contributed interpretation of clinical data and clinical reviews. All authors wrote the manuscript, synthesized the figures, and approved the final manuscript composition.
Carriano, A., Hoozeman, J. J. M., Van der Views, S. M., Van Horssen, J., DeVries, H. E., Rozemuller, A. J., et al. (2012). Neuroinflammation and BBB changes in CAA. Nauro Degen. Dis. 10, 329-331. doi: 10.1159/000334916

Castellano, G., Divella, C., Sallustio, F., Montinaro, V., Curcic, V., Zanicelli, A., et al. (2018). A transcriptomics study of hereditary angioedema attacks. J. Allergy Clin. Immunol. 142, 883-891. doi: 10.1016/j.jaci.2018.03.016

Chen, Z.-L., Revenko, A. S., Singh, P., MacLeod, A. T., Norris, E. H., and Strickland, S. (2017). Depletion of coagulation factor XII ameliorates brain pathology and cognitive impairment in Alzheimer disease mice. Blood 129, 2547-2556. doi: 10.1182/blood-2016-11-753202

Cho, H. S., Hyman, B. T., Greenberg, S. M., and Rebeck, G. W. (2001). Quantitation of ApoE domains in Alzheimer disease brain suggests a role for ApoE in A $\beta$ aggregation. J. Neuropathol. Exper. Neurol. 60, 342-348. doi: 10.1093/jnen/60.4.342

Chu, X., Jin, X., Parada, I., Pesic, A., Stevens, B., Barres, B., et al. (2010). Enhanced synaptic connectivity and epilepsy in C1q knockout mice. Proc. Natl. Acad. Sci. U.S.A. 107, 7975-7980. doi: 10.1073/pnas.0913449107

Cicardi, M., and Zuraw, B. L. (2018). Angioedemia due to bradykinin dysregulation. J Allergy Clin. Immunol. Practice. 6, 1132-1141. doi: 10.1016/j.jaip.2018.04.022

Conway, E. M. (2015). Reincarnation of ancient links between coagulation and complement. J. Thrombosis Haemostasis. 13(Suppl 1), 121-132. doi: $10.1111 /$ jth.12950

Corriveau, R., Huh, G., and Shatz, C. (1998). Regulation of class I MHC gene expression in the developing and mature CNS by neural activity. Neuron 21, 505-520. doi: 10.1016/S0896-6273(00)80562-0

Coulthard, L. G., Hawksworth, O. A., and Woodruff, T. M. (2018). Complement: the emerging architect of the developing brain. Trends Neurosci. 41, 373-384. doi: 10.1016/j.tins.2018.03.009

Cugno, M., Zanichelli, A., Foieni, F., Caccia, S., and Cicardi, M. (2009). $\mathrm{C} 1$ Inhibitor deficiency and angioedema: molecular mechanisms and clinical progress. Trends Mol Med. 15, 69-78. doi: 10.1016/j.molmed.2008. 12.001

Curd, J. G., Prograis, L. J. Jr., and Cochrane, C. G. (1980). Detection of active kallikrein in induced blister fluids of hereditary angioedema patients. J. Exp. Med. 152, 742-747. doi: 10.1084/jem.152.3.742

Cutler, P., Akuffo, E., Bodnar, W., Briggs, D. M., Davis, J. B., Debouck, C. M., et al. (2008). Proteomic identification and early validation of complement 1 inhibitor and pigment epithelium-derived factor: two novel biomarkers of Alzheimer's disease in human plasma. Proteomics Clin. Appl. 2, 457-471. doi: 10.1002/prca.200780101

Davis, A. E. I. I. I., Mejia, P., and Lu, F. (2008). Biological activities of C1 inhibitor. Mol. Immunol. 45, 4057-4063. doi: 10.1016/j.molimm.2008.06.028

De la Torre, J. C. (2004). Is Alzheimer's disease a neurodegenerative or a vascular disorder? Data, dogma and dialect. Lancet Neurol. 3, 184-190. doi: 10.1016/S1474-4422(04)00683-0

De Maat, S., Hofman, Z. L. M., and Maas, C. (2018). Hereditary angioedema: the plasma contact system out of control. J. Thromb. Haemost. 16, 1674-1685. doi: $10.1111 /$ jth.14209

Dejanovic, B., Huntley, M. A., De Maziere, A., Meilandt, W. J., Wu, T., Sriniveisan, K., et al. (2018). Changes in the synaptic proteome in tauopathy and rescue 
of tau-induced synapse loss by C1q antibodies. Neuron 100, 1322-1336. doi: 10.1016/j.neuron.2018.10.014

Dinamarca, M. C., Ravesh, A., Schneider, A., Fritzins, I., Fruh, S., Rem, P. D., et al. (2019). Complex formation of APP with $G_{A B A}$ receptors links axonal trafficking to amyloidogenic processing. Nat. Commun. 10, 1331-1348. doi: 10.1038/s41467-019-09164-3

Dosztányi, Z., Csizmók, V., Tompa, P., and Simon, I. (2005). The pairwise energy content estimated from amino acid composition discriminates between folded and intrinsically unstructured proteins. J. Mol. Biol. (2005) 347, 827-839. doi: 10.1016/j.jmb.2005.01.071

Eikelenboom, P., Hack, C. E., Rozemuller, J. M., and Stum, F. C. (1989). Complement activation in amyloid plaques in Alzheimer's disease. Virchow Arch. B Cell. Pathol. Incl Mol. Pathol. 56, 259-264. doi: 10.1007/BF02890024

Escuerdo-Esparaza, A., Kalchishkova, N., Kurbasic, E., Jiang, W. G., Blom, A. M., et al. (2013). The novel complement inhibitor human CUB and sushi multiple domains 1 (CSMD1) protein promotes factor I-mediated degradation of $\mathrm{C} 4 \mathrm{~b}$ and $\mathrm{C} 3 \mathrm{~b}$ and inhibits the membrane attack complex assembly. FASEB J. 27, 5083-5093. doi: 10.1096/fj.13-230706

Farfara, D., Feierman, E., Richards, A., Revenko, A. S., MacLeod, K. A., Norris, E. H., et al. (2019). Knockdown of circulating C1 inhibitor induces neurovascular impairment, glial cell activation, neuroinflammation and behavioral deficits. Glia 67, 1359-1373. doi: 10.1002/glia.23611

Ferreira, V. P., Pangburn, M. K., and Cortes, C. (2010). Complement control protein factor $\mathrm{H}$ : the good, the bad, the inadequate. Mol. Immunol. 47, 2187-2197. doi: 10.1016/j.molimm.2010.05.007

Fonseca, M. I., Chu, S., Pierce, A. L., Drubaker, W. F., Hauhart, R. E., Mastroeni, D., et al. (2016). Analysis of the putative role of CR1 in Alzheimer's disease: genetic association, expression and function. PLoS ONE. 11:e0149792. doi: 10.1371/journal.pone.0149792

Forneris, F., Wu, J., Xue, X., Riklin, D., Lin, Z., Sfyroera, G., et al. (2016). Regulators of complement activity mediate inhibitory mechanisms through common C3b binding mode. EMBO J. 35, 1133-1146. doi: 10.15252/embj.201593673

Franzmann, T. M., and Alberti, A. (2019). Prion-like low-complexity sequences: key regulators of protein solubility and phase behavior. J. Biol. Chem. 294, 7128-7136. doi: 10.1074/jbc.TM118.001190

Furtado, P. B., Huang, C. Y., Ihyembe, D., Hammond, R. A., Marsh, H. C., Perkins, S. J., et al. (2008). The partly folded back solution structure arrangement of the 30 SCR domains in human complement receptor type 1 permits access of its C3b and C4b ligands. J. Mol. Biol. 375, 102-118. doi: 10.1016/j.jmb.2007.09.085

Gaboriaud, C., Gregroy-Pauron, L., Teillet, F., Thielens, N. M., Bally, I., and Arlaud, G. J. (2011). Structure and properties of the $\mathrm{Ca}^{2+}$-binding CUB domain, a widespread ligand recognition unit involved in major biological functions. Biochem. J. 439, 185-193. doi: 10.1042/BJ20111027

Gaboriaud, C., Ling, W. L., Thielens, N. M., Bally, I., and Rossiy, Y. (2014). Deciphering the fine details of $\mathrm{C} 1$ assembly and activation mechanisms: "mission impossible"? Front. Immunol. 5:565. doi: 10.3389/fimmu.2014.00565

Gandy, S., Haroutunian, V., and DeKosky, S. T. (2013). CR1 and the "Vanishing amyloid" hypothesis of Alzheimer's disease. Biol. Psychiatry. 73, 393-395. doi: 10.1016/j.biopsych.2013.01.013

Garai, K., Verghese, P. M., Baban, B., Holtzman, D. M., and Friedan, C. (2014). The binding of apoliprotein $E$ to oligomers and fibrils of $A \beta$ alters the kinetics of amyloid aggregation. Biochemistry 53, 6323-6234. doi: 10.1021/bi5008172

Ghosh, S., Sil, T. B., Dolai, S., and Garai, K. (2019). High-affinity multivalent interactions between apolipoprotein $\mathrm{E}$ and oligomers of Ab. FEBS J. 286, 4737-4753. doi: 10.1111/febs.14988

Griciuc, A., Serrano-Pozo, A., Parrado, A. R., Lesinski, A. N., Asselin, C. N., Mullin, K., et al. (2013). Alzheimer's disease risk gene CD33 inhibits microglial uptake of amyloid beta. Neuron 78, 631-643. doi: 10.1016/j.neuron.2013.04.014

Gutierrez, M. A., Dwyer, B. E., and Franco, S. J. (2019). CSMD2 is a synaptic transmembrane protein that interacts with PSD95 and is required for neuronal maturation. eNeuro 6:e0434. doi: 10.1523/ENEURO.0434-18.2019

Guttman, M., Prieto, J. H., Croy, J. E., and Komives, E. A. (2010). Decoding of Lipoprotein - receptor Interactions; properties of ligand binding modules governing interactions with ApoE. Biochemistry 49, 1207-1232. doi: $10.1021 /$ bi9017208

Hack, C. E., Relan, A., Van Amersfoort, E. S., and Cicardi, M. (2012). Target levels of functional C1-inhibitor in hereditary angioedema. Allergy 67, 123-130. doi: $10.1111 /$ j.1398-9995.2011.02716.x
Halliday, M. R., Rege, S. V., Ma, Q., Zhao, Z., Miller, C. A., Winkler, E. A., et al. (2016). Accelerated pericyte degeneration and BBB breakdown in Apos4 carriers with AD. J. Cereb. Blood Flow Metabol. 36, 216-227. doi: $10.1038 / \mathrm{jcbfm} .2015 .44$

Havik, B., Le Hellard, S., Rietschel, M., Lybaek, H., Djurovic, S., Mattheisen, M., et al. (2011). The complement control-related genes CSMD1 and CSMD2 associate to schizophrenia. Biol. Psychiatry. 70, 35-42. doi: 10.1016/j.biopsych.2011.01.030

Hazrati, L. N., Van Cauwenberghe, C., Brooks, P. L., Brouwers, N., Ghani, M., Sato, C., et al. (2012). Genetic association of CR1 with Alzheimer's disease: a tentative disease mechanism. Neurobiol. Aging. 2949.e5-2949.e12. doi: 10.1016/j.neurobiolaging.2012.07.001

Hernandez, J. C. C., Bracko, O., Kersbergen, C. J., Muse, V., Hafl-Javaherian, M., Berg, M., et al. (2019). Neutrophil adhesion in brain capillaries reduces cortical blood flow and impairs memory function in Alzheimer's disease mouse models. Nat. Neurosci. 22, 413-420. doi: 10.1038/s41593-018-0329-4

Hong, S., Beja-Glasser, V. M., Nfonoyim, B. M., Frouin, A., Li, S., Ramakrishnan, S., et al. (2016). Complement and microglia mediate early synapse loss in Alzheimer mouse models. Science 352, 712-716. doi: 10.1126/science.aad8373

Hughes, M., Sawaya, M. R., Boyer, D. R., Goldschmitdt, L., Rodriguez, J. A., Cascio, D., et al. (2018). Atomic structures of low - complexity protein segments reveal kinked $\beta$ - sheets that assemble networks. Science 359, 698-701. doi: $10.1126 /$ science.aan6398

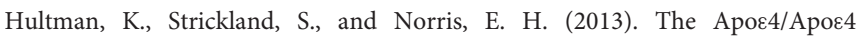
genotype potentiates vascular fibrinogen deposition in amyloid-laden vessels in the brains of AD patients. J. Cereb. Blood Flow Metabol. 33, 1251-1258. doi: $10.1038 / \mathrm{jcbfm} .2013 .76$

Iadecola, C. (2013). The pathobiology of vascular dementia. Neuron 80, 844-866. doi: 10.1016/j.neuron.2013.10.008

Java, A., Liszewski, M. K., Hourcade, D., Zhang, F., and Atkinson, J. P. (2015). Role of complement receptor 1 (CR1, CD35) on epithelial cells: a model for understanding complement - mediated damage in the kidney. Mol. Immunol. 67, 584-595. doi: 10.1016/j.molimm.2015.07.016

Jones, L., Holmans, P. S., Hamshere, M. L., Harold, D., Moskvina, V., Ivanov, D., et al. (2010). Genetic evidence implicates the immune system and cholesterol metabolism in the aetiology of Alzheimer's disease. PLOS ONE 5:e13950. doi: 10.1371/journal.pone.0013950

Jones, P. B., Adams, K. W., Rozkalne, A., Spires-Jones, T. L., Hshieh, T. T., Hashimoto, T., et al. (2011). Apolipoprotein E: isoform specific differences in tertiary structure and interaction with $\mathrm{A} \beta$ in human Alzheimer brain. PLoS ONE 6:e14586. doi: 10.1371/journal.pone.0014586

Jun, G., Naj, A. C., Beecham, G. W., Wang, L. S., Buros, J., Buxbaum, J. D., et al. (2010). Meta-analysis confirms CR1, CLU and PICALM as Alzheimer's disease risk loci and reveals interactions with APOE genotype. Arch. Neurol. 67, 1473-1484. doi: 10.1001/archneurol.2010.201

Kajdacsi, E., Jandrasics, Z., Veszeli, N., Mako, V., Koncz, A., Gulyas, D., et al. (2020). Patterns of $\mathrm{C} 1$ inhibitor - plasma serine protease complexes in healthy humans and hereditary angioedema patients. Front. Immunol. 11:794. doi: 10.3389/fimmu.2020.00794

Kanekiyo, T., Xu, H., Guojun, B. (2014). ApoE and $\mathrm{A} \beta$ in Alzheimer's disease: accidental encounters or partners? Neuron 81, 740-754. doi: 10.1016/j.neuron.2014.01.045

Kara, E., Marks, J. D., Roe, A. D., Commino, C., Fan, Z., Calvo-Rodriguez, M., et al. (2018). A flow cytometry-based in vitro assay reveals that formation of ApoE-A $\beta$ complexes depends on ApoE isoform and cell type. J. Biol. Chem. 293, 13247-13256. doi: 10.1074/jbc.RA117.001388

Kisler, L., Nelson, A. R., Montagne, A., and Zlokovic, B. V. (2017). Cerebral blood flow regulation and neurovascular dysfunction in Alzheimer's disease. Nat. Rev. Neurosci. 18, 419-434. doi: 10.1038/nrn.2017.48

Kolev, M. V., Ruseva, M. M., Harris, C. L., Morgan, B. P., and Donev, R. M. (2009). Implication of complement system and its regulators in Alzheimer's disease. Curr. Neuropharmacol. 7, 1-8. doi: 10.2174/1570159097876 02805

Kraus, D. M., Elliott, G. S., Chute, H., Honan, T., Pfenninger, K. H., Sanford, S. D., et al. (2006). CSMD1 is a novel multiple domain complementregulatory protein highly expressed in the central nervous system and epithelial tissues. J. Immunol. 176, 4419-4430. doi: 10.4049/jimmunol.176.7. 4419 
Kunkle, B. W., Grenier-Boly, B., Sims, R., Bis, J. C., Damotte, V., Naj, A. C., et al. (2019). Genomic meta-analysis of diagnosed Alzheimer's disease identifies new risk loci and implicates $\mathrm{A} \beta$, Tau, immunity and lipid processing. Nat Genetics. 51, 414-430. doi: 10.1038/s41588-019-0358-2

Lambert, J. C., Heath, S., Even, G., Campion, D., Sleegers, K., Hiltunen, M., et al. (2009). Genome-wide association study identifies variants at CLU and CR1 associated with Alzheimer's disease. Nat. Genetics. 41, 1094-1098. doi: $10.1038 /$ ng.439

Lian, H., and Zheng, H. (2016). Signaling pathways regulating neuron - glia interaction and their implications in Alzheimer's disease. J. Neurochem. 136, 475-491. doi: 10.1111/jnc.13424

Litvinchuk, A., Wan, Y. W., Swartzlander, D. B., Chen, F., Cole, A., Propson, N. E., et al. (2018). Complement $\mathrm{C} 3 \mathrm{aR}$ inactivation attenuates tau pathology and reverses an immune network deregulated in tauopathy models and Alzheimer's disease. Neuron 100, 1337-1353. doi: 10.1016/j.neuron.2018.10.031

Lucin, K. M., and Wyss-Coray, T. (2009). Immune activation in brain aging and neurodegeneration: too much or too little? Neuron 64, 110-122. doi: 10.1016/j.neuron.2009.08.039

Maas, C., Grovers-Riemslag, J. W. P., Bouma, B., and Schiks, B. (2008). Misfolded proteins activate factor XII in humans, leading to kallikrein formation without initiating coagulation. J. Clin. Invest. 118, 3208-3218. doi: 10.1172/JCI35424

Magdalon, J., Mansur, F., Teles e Silva, A. L., de Goes, V. A., and Reiner, O., Sertie, AL. (2020). Complement system in brain architecture and developmental disorders. Front. Neurosci. 14:23. doi: 10.3389/fnins.2020.00023

Magliozi, R., Haemetner, S., Facchiano, F., Marastoni, D., Rossi, S., Castellaro, M., et al. (2019). Iron homeostasis, complement, and coagulation cascade as CSF signature of cortical lesions in early multiple sclerosis. Ann. Clin. Transl. Neurol. 6, 2150-2163. doi: 10.1002/acn3.50893

Makou, E., Herbert, A. P., and Barlow, P. (2015). Creating functional sophistication from simple protein building blocks, exemplified by factor $\mathrm{h}$ and the regulators of complement activation. Biochem. Soc. Trans. 43, 812-818. doi: 10.1042/BST20150074

Martin, B. K. (2007). Transcriptional control of complement receptor gene expression. Immunol. Res. 39, 146-159. doi: 10.1007/s12026-007-0078-Z

Matsuo, K., Shindo, A., Niwa, A., Tabei, K., Akatsu, H., Hashizume, Y., et al. (2017). Complement activation in capillary CAA. Dement. Geriatr. Cogn. Disord. 446, 343-353. doi: 10.1159/000486091

Mendiola, A. S., Ryu, J. K., Bardehle, S., Meyer-Franke, A., Ang, K. K., Wilson, C., et al. (2020). Transcriptional profiling and therapeutic targeting of oxidative stress in neuroinflammation. Nat. Immunol. 21, 513-524. doi: 10.1038/s41590-020-0654-0

Merle, N. S., Church, S. E., Fremeaux-Bacchi, V., Roumeni, L. T., et al. (2015a). Complement system part I molecular mechanisms of activation and regulation. Front Immunol. 6:262. doi: 10.3389/fimmu.2015.00262

Merle, N. S., Noe, R., Halbwachs-Mecarelli, L., Fremeaux-Bacchi, V., and Roumeni, L. T. (2015b). Complement system part II role in immunity. Front. Immunol. 6:257. doi: 10.3389/fimmu.2015.00257

Merlini, M., Rafalsky, V. A., Rios Coronado, P. E., Gill, T. M., Ellisman, M., Muthukumar, G., et al. (2019). Fibrinogen induces microglia-mediated spine elimination and cognitive impairment in an Alzheimer's disease model. Neuron. 101, 1099-1108. doi: 10.1016/j.neuron.2019.01.014

Miles, L. A., Hermans, S. J., Crespi, G. A. N., Gooi, J. H., Doughty, L., Nero, T. L., et al. (2019). Small molecule binding to Alzheimer risk factor CD33 promotes $\mathrm{A} \beta$ phagocytosis. iScience 19, 110-118. doi: 10.1016/j.isci.2019. 07.023

Miyazawa, Y., Uekita, T., Hiraoka, N., Fujii, S., Kosuge, T., Kanai, Y., et al. (2010). CUB domain-containing protein 1, a prognostic factor for human pancreatic cancers, promotes cell migration and extracellular matrix degradation. Cancer Res. 70, 5136-5146. doi: 10.1158/0008-5472.CAN-100220

Mizukami, T., Kohno, T., and Hattori, M. (2016). CUB and sushi multiple domain 3 regulates dendrite development. Neurosci. Res. 111, 11-17. doi: 10.1016/j.neures.2016.03.003

Molliex, A., Temirov, J., Lee, J., Kanegaraj, A. P., Kim, H. J., Mittag, T., et al. (2015). Phase separation by low complexity domains promotes stress granule assembly and drives pathological fibrillization. Cell 163, 123-133. doi: 10.1016/j.cell.2015.09.015
Montagne, A., Nation, D. A., and Blokovic, B. V. (2020). Apoe4 leads to BBB dysfunction predicting cognitive decline. Nature 581, 71-76. doi: 10.1038/s41586-020-2247-3

Morgan, B. P. (2018). Complement in the pathogenesis of Alzheimer's disease. Semin. Immunopathol. 40, 113-124. doi: 10.1007/s00281-017-0662-9

Muenchhoff, J., Song, F., Poljak, A., Crawford, J. D., Mather, K. A., Kochan, N. A., et al. (2015). Plasma protein profiling of mild cognitive, impairment and Alzheimer's disease across two independent cohorts. J. Alzheimer's Dis. 43, 1355-1373. doi: 10.3233/JAD-141266

Murphy, K. M., and Weaver, C. (2016). Janeway's Immunobiology. New York, NY: Garland science.

Nan, R., Tetchner, S., Rodriguez, E., Pao, P. J., Goe, J., Lengyel, I., et al. (2013). Zinc - induced self-association of complement C3b and factor H. J. Biol. Chem. 288, 19197-19210. doi: 10.1074/jbc.M113.476143

Nation, D. A., Sweeney, M. D., Montagne, A., Sagare, A. D., D’orazio, L. M., Pachicano, M., et al. (2019). BBB breakdown is an early biomarker of human cognitive dysfunction. Nat Med. 25, 270-276. doi: 10.1038/s41591-018-0297-y

Nguyen, P. T., Dorman, L. C., Pan, S., Vainchlein, I. D., Han, R. T., Inoue, H. D., et al. (2020). Microglial remodeling of the extracellular matrix promotes synaptic plasticity. Cell 182, 1-16. doi: 10.1016/j.cell.2020.05.050

Nilsson, S. C., Sim, R. B., Lea, S. M., Fremeaux-Bach, V., and Blom, A. M. (2011). Complement factor I in health and disease. Mole Immunol. 48, 1611-1620. doi: 10.1016/j.molimm.2011.04.004

Nishitsuji, K., Hosono, T., Nakamura, T. B. G., Bu, G., Michikawa, M., et al. (2011). Apolipoprotein E regulates the integrity of tight junctions in an isoform dependent manner in an in vitro BBB model. J. Biol. Chem. 286, 17536-17542. doi: 10.1074/jbc.M111.225532

Nussberger, J., Cugno, M., Amstutz, C., Cicardi, M., Pellacani, A., and Agostoni, A. (1998). Plasma bradykinin in angioedema. Lancet 351, 1693-1697. doi: 10.1016/S0140-6736(97)09137-X

Nussberger, J., Cugno, M., Cicardi, M., and Agostoni, A. (1999). Local bradykinin generation in hereditary angioedema. J. Allergy Clin. Immunol. 104, 1321-1322. doi: 10.1016/S0091-6749(99)70030-8

Oh, S. B., Kim, J. S., and Park, S. (2020). Associative interactions among zinc, apoliprotein $\mathrm{E}$ and $\mathrm{A} \beta$ in the amyloid pathology. Int. J. Mole Sci. 21, 802-816. doi: $10.3390 /$ ijms 21030802

Petty, H. R., Smith, L. M., Fearon, D. T., and McConnell, H. M. (1980). Lateral distribution and diffusion of the $\mathrm{C} 3 \mathrm{~b}$ receptor of complement, HLA probes in peripheral blood leukocytes. Proc. Natl. Acad. Sci. U.S.A. 77, 6587-6591. doi: 10.1073/pnas.77.11.6587

Presumey, J., Bialas, A. R., and Carroll, M. C. (2018). Complement system in neural synapse elimination in development and disease. Adv. Immunol. 135, 53-79. doi: 10.1016/bs.ai.2017.06.004

Puigdellivol, M., Allendorf, D. H., and Brown, G. C. (2020). Sialyation and Galactin - 3 in microglia-mediated neuroinflammation and neurodegeneration. Front. Cell. Neurosci. 14:162. doi: 10.3389/fncel.2020. 00162

Rice, H. C., de Malmazet, D., Schreurs, A., Frere, S., Van Molle, I., Volkov, A. N., et al. (2019). Secreted amyloid- $\beta$ precursor protein functions as a $\mathrm{GABA}_{\mathrm{B}} \mathrm{R} 1 \mathrm{a}$ ligand to modulate synaptic transmission. Science 363:eaa04827. doi: $10.1126 /$ science.aao4827

Rogers, J., Cooper, N. R., Webster, S., Schulz, J., McGeer, P. L., Styren, S. D., et al. (1992). Complement activation by beta-amyloid in Alzheimer's disease. Proc. Natl. Acad. Sci. U.S.A. 89, 10016-10024. doi: 10.1073/pnas.89. 21.10016

Sandri, T. L., Adukpo, S., Giang, D. P., Nguetse, C. N., Andrade, S. A., Van Tong, H., et al. (2017). Geographical distribution of complement receptor type 1 variants and their associated disease risk. PLOS ONE 12:e0175973. doi: 10.1371/journal.pone.0175973

Schjeide, B. M. M., Schnack, C., Lambert, J. C., Lill, C. M., Kirchheiner J., Tuniani, H., et al. (2011). The role of CLU, CR1 and PICALM in $\mathrm{AD}$ risk and CSF biomarkers. Arch. Gen. Psychiatry. 68, 207-213. doi: 10.1001/archgenpsychiatry.2010.196

Schmaier, A. H. (2019). The hereditary angioedema syndromes. J. Clin. Invest. 129, 66-68. doi: 10.1172/JCI125378

Schmidt, C. Q., Ederveen, A. L. H., Harder, M. J., Wuhrer, M., Stehle, T., and Blaum, B. S. (2018). Biophysical analysis of sialic acid recognition 
by the complement regulator factor H. Glycobiology 28, 765-773. doi: 10.1093/glycob/cwy061

Sekar, A., Bialas, A. R., deRivera, H., Davis, A., Hammond, T. R., Kamitaki, N., et al. (2016). Schizophrenia risk from complex variation of complement component 4. Nature 530, 177-183. doi: 10.1038/nature16549

Shen, L., Liao, L., Chen, C., Guo, Y., Song, D., Wang, Y., et al. (2017). Proteomics analysis of blood serums from Alzheimer's disease patients using iTRAQ labeling technology. J. Alzheimers Dis. 56, 361-378. doi: 10.3233/JAD-160913

Shen, Y., Lue, L. F., Yang, L. B., Rohrer, A., Kuo, Y., Strohmeyer, R., et al. (2001). Complement activation by neurofibrillary tangles in Alzheimer's disease. Neurosci. Lett. 305, 165-168. doi: 10.1016/S0304-3940(01) 01842-0

Shen, Y., Yang, L., and Li, R. (2013). What does complement do in Alzheimer's disease? Old molecules with new insights. Transl. Neurodegen. 2, 21-32. doi: 10.1186/2047-9 158-2-21

Sheng, M., Sabatini, B. L., and Sudhof, T. C. (2012). Synapses and AD. Cold Spring Harbor Lab. 4:a005777. doi: 10.1101/cshperspect.a005777

Shibiyama, Y., Joseph, K., Nakazawa, Y., Ghebreihiwet, B., Peershke, E. L., and Kaplan, A. P. (1999). Zinc - dependent activation of the plasma kinin forming cascade by aggregated $\beta$-amyloid protein. Clin. Immunol. 90, 89-99. doi: 10.1006/clim.1998.4621

Singh, P., Chen, Z.-L., Ghosh, D., Strickland, A., and Norris, E. H. (2020). Increased plasm bradykinin level is associated with cognitive impairment. Neurobiol. Dis. 139:104833. doi: 10.1016/j.nbd.2020.104833

Singhrao, S. K., Neal, J. W., Rushmere, N. K., Morgan, B. P., and Gasque, P. (1999). Differential expression of individual complement regulators in the brain and choroid plexus. Lab. Invest. 79, 1247-1259.

Späth, P. J., Wüthrich, B., and Bütler, R. (1984). Quantification of C1-inhibitor functional activities by immunodiffusion assay in plasma of patients with hereditary angioedema - evidence of a functionally critical level of C1-inhibitor concentration. Complement 1, 147-159. doi: 10.1159/000467830

Steen, V. M., Nepal, C. N., Ersland, K. M., Hold, R., Naevdal, M., Ratvik, J. M., et al. (2013). Neuropsychological deficits in mice depleted of the schizophrenia susceptibility gene CSMD1. PLoS ONE 8:e79501. doi: 10.1371/journal.pone.0079501

Stevens, B., Allen, N. J., Vazquez, L. E., Howell, G. R., Christopherson, K. S., Nouri, N., et al. (2007). The classical complement cascade mediates CNS synapse elimination. Cell 131, 1164-1178. doi: 10.1016/j.cell.2007. 10.036

Stevens, B., Tenner, A., and Woodruff, T. M. (2018). New tricks for an ancient system: physiological and pathological roles of complement in the CNS. Mol. Immunol. 102, 3-13. doi: 10.1016/j.molimm.2018. 06.264

Strickland, S. (2018). Blood will out: vascular contributions to Alzheimer's disease. J. Clin. Invest. 128, 556-563. doi: 10.1172/JCI 97509

Suidan, G. L., Singh, P. K., Patel-Hett, S., Chen, Z. L., Volfson, D., Yamohimoto, H., et al. (2018). Abnormal clotting of the intrinsic / contact pathway in Alzheimer disease patients is related to cognitive ability. Blood Adv. 2, 954-962. doi: 10.1182/bloodadvances.2018017798

Tacnet-Delorme, P., Chevallier, S., and Arlaud, G. J. (2001). B-amyloid fibrils activate the $\mathrm{C} 1$ complex of complement under physiological conditions: evidence for a binding site for $\mathrm{Ab}$ on the $\mathrm{C} 1 \mathrm{q}$ globular regions. J. Immunol. 167, 6374-6381. doi: 10.4049/jimmunol.167.11.6374

Terai, K., Walker, D. G., McGeer, E. G., and McGeer, P. L. (1997). Neurons express proteins of the classical complement pathway in Alzheimer's disease. Brain Res. 769, 385-390. doi: 10.1016/S0006-8993(97)00849-4

Thambisetty, M., An, M., Nalls, M., Sojkorci, J., Swaminathan, S., Zhou, Y., et al. (2013). Effect of complement CR1 on brain amyloid burden during aging and its modification by APOE genotype. Biol. Psychiatry. 73, 422-428. doi: 10.1016/j.biopsych.2012.08.015

Tsiolaki, P. L., Katsafana, A. D., Baltoumas, F. A., Louros, N. N., and Iconomidou, V. A. (2019). Hidden aggregation hot-spots on human apoliprotein E: a structural study. Int. J. Mole Sci. 20, 1-14. doi: 10.3390/ijms20092274

Veerhuis, R., Nielsen, H. M., and Tenner, A. (2011). Complement in the brain. Mol. Immunol. 48, 1592-1603. doi: 10.1016/j.molimm.2011.04.003
Verghese, P. B., Castellano, J. M., Garai, K., Baban, B., Holtzman, D. M., and Frieden, C. (2013). ApoE influences A $\beta$ clearance despite minimal apoE / $\mathrm{A} \beta$ association in physiological conditions. Proc Natl Acad Sci. U.S.A. 110, E1807-1816. doi: 10.1073/pnas.1220484110

Wallis, R. (2007). Interactions between mannose-binding lectin and MASP's during complement activation by the lectin pathway. Immunobiology 212, 289-299. doi: 10.1016/j.imbio.2006.11.004

Wilton, D. K., Dissing-Olesen, L., and Stevens, B. (2019). Neuron-glia signaling in synapse elimination. Ann. Rev. Neurosci. 42, 107-112. doi: 10.1146/annurev-neuro-070918-050306

Windfuhr, J. P., Alsenz, J., and Loos, M. (2005). The critical concentration of C1-esterase inhibitor (C1-INH) in human serum preventing auto-activation of the first component of complement (C1). Mol. Immunol. 42, 657-663. doi: 10.1016/j.molimm.2004.09.025

Woo, J. J., Pouget, J. G., Zai, C. C., and Kennedy, J. L. (2020). The complement system in schizophrenia: where are we now and what's next? Mol. Psychiatry. 25, 114-130. doi: 10.1038/s41380-019-0479-0

Wu, J., Wu, Y. Q., Ricklin, D., Janssen, B. J., Lambris, J. D., Gros, P., et al. (2009). Structure of C3b-factor $\mathrm{H}$ and implications for host protection by complement regulators. Nat. Immunol. 10, 728-733. doi: 10.1038/ni.1755

Xue, B., Dunbrack, R. L., Williams, R. W., Dunker, A. K., Uversky, V. N. (2010). PONDR-FIT: a meta-predictor of intrinsically disordered amino acids. Biochim. Biophys. Acta. 1804, 996-1010. doi: 10.1016/j.bbapap.2010. 01.011

Xue, X., Wu, J., Ricklin, D., Forneris, F., DiCrescenzio, O., Schmidt, C. G., et al. (2016). Regulator-dependent mechanisms of C3b processing by factor I allow differentiation of immune responses. Nat. Struct. Mol. Biol. 24, 643-651. doi: 10.1038/nsmb.3427

Yamamoto, T., Choi, H., and Ryan, R. O. (2008). Apolipoprotein E isoform-specific binding to the low-density lipoprotein receptor. Anal. Biochem. 372, 222-226. doi: 10.1016/j.ab.2007.09.005

Yan, M. H., Wang, X., and Ahu, X. (2013). Mitochondrial defects and oxidative stress in AD and PD. Free Rad Biol Med. 62, 90-101. doi: 10.1016/j.freeradbiomed.2012.11.014

Yang, A. C., Stevens, M. Y., Chen, M. B., Lee, D. L., Stahli, D., Gate, D., et al. (2020). Physiological blood-brain transport is impaired with age by a shift in transcytosis. Nature 583, 425-430. doi: 10.1038/s41586-0202453-z

Yang, J. T., Kuo, Y. C., Chen, I. Y., Rajesh, R., Lou, Y. I., Hsu, J. P., et al. (2019). Protection against neurodegeneration in the hippocampus using sialic acid- and 5-HT-moduline-conjugated lipopolymer nanoparticles. ACS Biomater Sci. Eng. 5, 1311-1320. doi: 10.1021/acsbiomaterials.8b 01334

Yang, L., Li, Y., Bhattacharya, A., and Zhang, Y. (2016). A plasma proteolysis pathway comprising blood coagulation proteases. Oncotarget 7, 40919-40938. doi: 10.18632 /oncotarget.7261

Yasojima, K., McGreer, E. G., and McGeer, P. L. (1999). Complement regulators $\mathrm{C} 1$ inhibitor and CD59 do not significantly inhibit complement activation in Alzheimer's disease. Brain Res. 833, 297-301. doi: 10.1016/S0006-8993(99)01514-0

Zamolodchikov, D., Chen, Z.-L., Conti, B., Kenne, T., and Strickland, S. (2015). Activation of the factor XII - driven contact system in Alzheimer's disease patient and mouse model plasma. Proc. Natl. Acad. Sci. U.S.A. 112, 4068-4073. doi: $10.1073 /$ pnas. 1423764112

Zenaro, E., Piacentino, G., and Constantin, G. (2017). The BBB in Alzheimer's disease. Neurobiol. Dis. 107, 41-56. doi: 10.1016/j.nbd.2016.07.007

Zhang, D. F., Li, J., Wu, H., Cui, Y., Bi, R., Zhou, H. J., et al. (2016). CFH variants affect structural and functional brain changes and genetic risk of Alzheimer's disease. Neuropsychopharmacology 41, 1034-1045. doi: 10.1038/npp.2015.232

Ziccardi, R. J. (1981). Activation of the early components of the classical complement pathway under physiological conditions. J. Immunol. 126, $1768-1773$.

Ziccardi, R. J. (1982). A new role for C-1-inhibitor in homeostasis: control of activation of the first component of human complement. J. Immunol. 28, 2505-2508.

Ziccardi, R. J., and Cooper, N. R. (1979). Active disassembly of the first complement component $\mathrm{C} 1$ by $\mathrm{C} 1$ inhibitor. J. Immunol. 123, 788-792. 
Zlokovic, B. V. (2011). Neurovascular pathways to neurodegeneration in Alzheimer's disease and other disorders. Nat. Rev. Neurosci. 12, 733-738. doi: $10.1038 / \mathrm{nrn} 3114$

Zsolt, D., Olah, Z., Janosi-Mozes, E., Szegedi, V., Kalman, J., Hunya, A. G., et al. (2020). Alzheimer risk factors age and female sex induce cortical Ab aggregation by raising extracellular zinc. Mol. Psychiatry. 25:5S. doi: 10.1038/s41380-020-0800-y

Conflict of Interest: CS is an unpaid consultant to IPPIN Biomarkers and will become a shareholder of the C-Corporation should it obtain Series A financial backing.
The remaining author declares that the research was conducted in the absence of any commercial or financial relationships that could be construed as a potential conflict of interest.

Copyright $\odot 2021$ Peoples and Strang. This is an open-access article distributed under the terms of the Creative Commons Attribution License (CC BY). The use, distribution or reproduction in other forums is permitted, provided the original author(s) and the copyright owner(s) are credited and that the original publication in this journal is cited, in accordance with accepted academic practice. No use, distribution or reproduction is permitted which does not comply with these terms. 